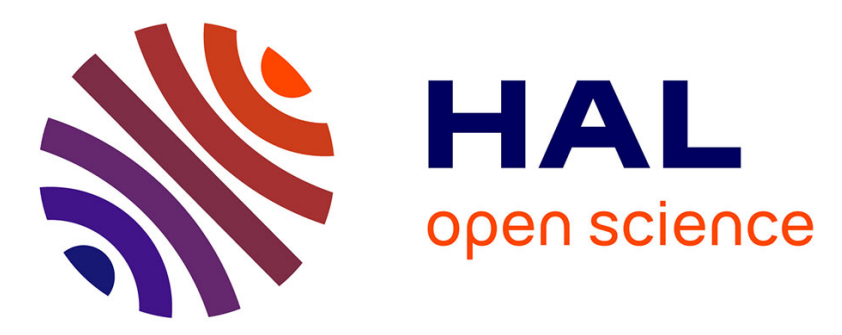

\title{
A three-dimensional investigation of the effects of excitation frequency and sheath gas mixing in an atmospheric-pressure inductively coupled plasma system \\ V Colombo, E Ghedini, P Sanibondi
}

\section{- To cite this version:}

V Colombo, E Ghedini, P Sanibondi. A three-dimensional investigation of the effects of excitation frequency and sheath gas mixing in an atmospheric-pressure inductively coupled plasma system. Journal of Physics D: Applied Physics, 2010, 43 (10), pp.105202. 10.1088/0022-3727/43/10/105202 . hal-00629942

\section{HAL Id: hal-00629942 \\ https://hal.science/hal-00629942}

Submitted on 7 Oct 2011

HAL is a multi-disciplinary open access archive for the deposit and dissemination of scientific research documents, whether they are published or not. The documents may come from teaching and research institutions in France or abroad, or from public or private research centers.
L'archive ouverte pluridisciplinaire HAL, est destinée au dépôt et à la diffusion de documents scientifiques de niveau recherche, publiés ou non, émanant des établissements d'enseignement et de recherche français ou étrangers, des laboratoires publics ou privés. 


\title{
A three-dimensional investigation of the effects of excitation frequency and sheath gas mixing in an atmospheric-pressure inductively-coupled plasma system
}

\author{
V Colombo, E Ghedini, P Sanibondi
}

Dipartimento di Ingegneria delle Costruzioni Meccaniche, Nucleari, Aeronautiche e di Metallurgia (DIEM), Alma Mater Studiorum - Università di Bologna, Via Saragozza 8, 40123 Bologna, Italy

E-mail: paolo.sanibondi@unibo.it

\begin{abstract}
A three dimensional numerical model for the simulation of the behavior of a commercial inductively coupled plasma (ICP) torch with non-axisymmetric reaction chamber has been developed, taking in account turbulence and gas mixing through RNG $\mathrm{k}-\epsilon$ theory and the combined diffusion approach of Murphy, respectively.

The effects of changing coil current frequency, the hydrogen mixing in an argon primary gas and the flow patterns and temperature distributions which take place in a reaction chamber with a lateral gas outlet system and two observation windows have been investigated, with the final aim of setting up a computational tool able to predict the main features of plasma assisted treating and processing of injected raw materials.

Three-dimensional shapes of the temperature, velocity and mass fraction fields have been obtained and analyzed for an $\mathrm{Ar}-\mathrm{H}_{2}$ mixture at atmospheric pressure. Computations have been performed with two different coil current frequencies, i.e. 3 $\mathrm{MHz}$ and $13.56 \mathrm{MHz}$, showing that for the lower value the 3-D effects in the discharge are enhanced.

Accurate mixing and demixing mechanisms have been investigated in both cases, including considerations on the relative importance of different thermal diffusion contributions due to mole fraction and temperature gradients.

Temperature distributions in the reaction chamber for different cases have been correlated to different flow patterns and recirculation flows which take place as a consequence of the non-axisymmetry of the reaction chamber.
\end{abstract}

PACS numbers: 52.75.Hn Plasma torches - 52.65.-y Plasma simulation - 52.80.Pi Highfrequency and RF discharges

Submitted to: J. Phys. D: Appl. Phys.

\section{Introduction}

Inductively coupled plasma torches are widely used as high-temperature, high-purity sources in numerous applications such as powder spheroidization, synthesis of nano- 
powders and deposition of protective coatings. The success of a given process depends directly on the plasma temperature and velocity fields in the discharge, which in turn depend on the geometric and operating parameters of the system; for example mass flow rate of different gases, Joule power coupled to the plasma, coil current frequency, gas composition, pressure; thus, characterization of the plasma thermo-fluid-dynamic fields and knowledge of the influence of such parameters on plasma properties is of primary importance [1].

Since relevant progress has recently been made in computer capability which allows for the implementation of more and more sophisticated approaches $[2,3,4,5,6]$, numerical modeling represents a valid and powerful tool to predict the characteristic behavior of plasma sources.

Increasing attention is given to three-dimensional effects in temperature and velocity fields which arise taking into account realistic three-dimensional geometries: e.g. the effects of the real coil shape $[3,7,8,9,10]$, the detailed inlet gas region of the torch [11] and the transverse injection of cold jets $[12,13,14]$ have already been studied. Moreover, the effect of changing fluid-dynamic and electromagnetic operating conditions in 3D geometries has been reported in [15].

The scope of this study is to investigate by means of a fully three-dimensional code the influence of different coil current frequencies on thermo-fluid-dynamic fields, the hydrogen mixing in an argon primary gas and the flow patterns and temperature distributions which take place in a reaction chamber with a lateral gas outlet system and two observation windows suitable for diagnostics.

The induction torch chosen for this study is one of the most common commercial models: a Tekna Plasma Systems Inc. model PL-35.

A previous work by some of the authors [16] has shown that torch configurations with high-frequency and high turn coil density can result in almost axisymmetric plasma discharges inside the torch. Thus, the first goal of this paper is to give deeper insights about the influence of frequency alone on the three-dimensional shape of temperature, velocity and composition fields inside the torch.

This study is in line with the fact that the same torch can be operated with different coil current frequencies, depending on the configuration of the RF generator connected thereto, and that typical values for this parameter in a Tekna PL-35 torch are $3 \mathrm{MHz}$ and $13.56 \mathrm{MHz}$. We concentrated on these values for coil current frequency since they are commonly used in many systems for both research and production purposes and they are dedicated by law to industrial applications in many countries.

The second goal and third goals of this work arise from the fact that different gas mixtures (inert, oxidant, reducing) can be injected in the torch $[17,18]$ and that in powder processing applications the induction torch is usually used in connection with a reaction chamber in order to obtain conditions for pressure and gas composition suitable for the purpose of treating and processing injected raw materials.

In powder spheroidization, waste treatment and nano-powder production an argonhydrogen mixture is usually used $[19,20]$ since the higher specific heat and the higher 
thermal conductivity of hydrogen results in a higher plasma enthalpy and in a higher heat flux to the particles. Argon-hydrogen is usually injected as sheath gas and hydrogen has small mole fractions (less than 10\%) to preserve the quartz tube from overheating. The second goal is thus to accurately investigate the diffusion of hydrogen from the sheath gas, since powder treatment processes are very sensitive to hydrogen content in the core of the discharge.

The diffusion of gases in induction torches has been studied in many papers with different approaches, including combined diffusion [5] and chemical non-equilibrium [21]. Some works by Tanaka [22, 23], Watanabe et al [24, 25, 26] and other authors [4, 27] implemented the second approach, obtaining accurate prediction of species distribution in the torch: as a drawback, in those papers, demixing due to mole fraction and temperature gradients has not been investigated. On the contrary, a combined diffusion approach has been used by Chen [28], but the effects of demixing have not been discussed in detail, although results for the mass fraction of hydrogen shows that it occurs in the near-wall region.

In this paper we considered diffusion of hydrogen from the secondary gas with a combined diffusion approach in a three-dimensional framework, including investigation of different relevant demixing mechanisms (mole fraction and temperature gradients).

The third goal of this paper is to predict flow patterns inside a non-axisymmetric reaction chamber with a lateral outlet gas system and investigate the influence of advection on temperature distribution in the tail of the plasma discharge. This type of investigation is of interest for nano-powder synthesis applications, where main processes (particle nucleation and growth) take place in the low temperature (over-saturated) zone located in the downstream region of the torch [18, 29].

Inductively coulpled plasma torches have been investigated also using thermal nonequilibrium approaches [30, 25, 23]: these studies have shown that for pressure higher that 0.5 bar NLTE conditions exists only in the discharge fringes (near cold gas injection regions and torch walls) where high temperature gradients exist. Moreover, for argonhydrogen mixtures Ye et al [31] showed that NLTE effects are much less pronounced that in the case of pure argon, as a result of higher electron-heavy particle cross section for hydrogen species than for argon species. Consequently, in this paper, since an atmospheric pressure argon-hydrogen plasma has been considered, a LTE approach has been chosen.

\section{Modeling approach}

The following hypothesis are assumed in the present calculations:

(i) Plasma is in local thermodynamic equilibrium (LTE);

(ii) Combined diffusion approach of Murphy is used to model the diffusion in a mixture of two non-reactive gases;

(iii) Turbulent effects are taken in account through RNG $k-\epsilon$ model; 
(iv) Plasma is optically thin and radiative losses are taken in account considering only the presence of argon in the mixture;

(v) Composition is computed taking in account six species: $\mathrm{Ar}, \mathrm{Ar}{ }^{+}, \mathrm{H}_{2}, \mathrm{H}, \mathrm{H}^{+}$and electrons;

(vi) Viscous dissipation term in the energy equation is neglected;

(vii) Displacement currents are neglected.

\subsection{Governing equations}

The physical behavior of the plasma has been modeled removing any axisymmetric assumption and a fully 3D model has been implemented in the FLUENT ${ }^{\circledR}$ environment. The governing equations can be written as

$$
\begin{aligned}
& \nabla \cdot(\rho \boldsymbol{v})=0 \\
& \nabla \cdot(\rho \boldsymbol{v} \boldsymbol{v})=-\nabla p+\nabla \cdot \tau+\rho \boldsymbol{g}+F_{L} \\
& \nabla \cdot(\rho \boldsymbol{v} h)=-\nabla \cdot\left(\frac{k_{e f f}}{c_{p}} \nabla h\right)+\nabla \cdot\left(\sum_{i} h_{i}\left(\boldsymbol{J}_{i}+\frac{k}{c_{p}} \nabla \bar{Y}_{i}\right)\right)+P_{J}-Q_{r}(3)
\end{aligned}
$$

where $\rho$ is the plasma density, $\boldsymbol{v}$ is the velocity, $p$ is the pressure, $\tau$ is the stress tensor, $\boldsymbol{g}$ is the gravitational force, $h$ is the total enthalpy, $k_{\text {eff }}$ is the effective thermal conductivity, $c_{p}$ is the specific heat at constant pressure and $Q_{r}$ is the volumetric radiative loss; $\bar{Y}_{i}$ and $\boldsymbol{J}_{\boldsymbol{i}}$ are the mass fraction and the diffusion current of the $i$-th gas. The Lorentz forces $F_{L}$ and Joule dissipation $P_{J}$ can be written as

$$
\begin{aligned}
& F_{L}=\frac{1}{2} \Re\left(\boldsymbol{J} \times \boldsymbol{B}^{*}\right) \\
& P_{J}=\frac{1}{2} \Re\left(\boldsymbol{J} \cdot \boldsymbol{E}^{*}\right)
\end{aligned}
$$

where $\boldsymbol{J}$ is the complex phasor for the current density induced in the plasma, $\boldsymbol{B}$ is the magnetic induction complex phasor, $\boldsymbol{E}$ is the electric field complex phasor. The superscript "*" indicates the complex conjugate. Using the commercial software FLUENT $^{\circledR}$ to solve fluid equations, the Lorentz forces, ohmic heating, radiative loss terms and energy sources due to diffusion must be taken into account by using suitable User-Defined Functions written in $\mathrm{C}$ language.

Diffusion of gases can be described using the combined approach of Murphy [5, 6], assuming local chemical equilibrium. This method allows to treat diffusion of gases containing a large number of species (six species in our case) solving only (N-1) equations, where $\mathrm{N}$ is the number of gases in the mixture ( $\mathrm{N}=2$ in our simulations), leading to a great reduction in computational time. Moreover, this method can be considered as accurate as a fully multi-component diffusion approach provided that local chemical equilibrium has been reached; as shown by Rini et al [32] for air plasmas, this 
conditions is verified in ICP torches for pressure greater that 0.3 bar. The FLUENT ${ }^{(}$ software provides modules for the solution of diffusion equations with the following form:

$$
\nabla \cdot\left(\rho \boldsymbol{v} \bar{Y}_{i}\right)+\nabla \cdot \boldsymbol{J}_{i}=0
$$

where diffusion currents $\boldsymbol{J}_{i}$ can be written as

$$
\boldsymbol{J}_{i}=-\left(\frac{\mu_{t}}{S c}+\rho D_{i}^{Y}\right) \nabla \bar{Y}_{i}-D_{i}^{T} \nabla \ln T
$$

where $\bar{Y}_{i}, D_{i}^{Y}$ and $D_{i}^{T}$ are mass fraction, the mass fraction diffusion coefficient and the temperature diffusion coefficient for the $i$-th gas, respectively; $\mu_{t}$ is the turbulent viscosity and $S c$ is the Schmidt number taken equal to 0.7 .

Using the same symbols introduced by Murphy [6] and taking $\nabla \bar{x}_{i}=$ $\left(\partial \bar{x}_{i} / \partial \bar{Y}_{i}\right) \nabla \bar{Y}_{i}+\left(\partial \bar{x}_{i} / \partial T\right) \nabla T$, the combined diffusion equations given by Murphy for a binary mixture composed by the gases $i$ and $j$ can be solved in the FLUENT $^{(}$ environment setting

$$
\begin{aligned}
& D_{i}^{Y}=\frac{n^{2}}{\rho^{2}} \bar{m}_{i} \bar{m}_{j} \bar{D}_{i j}^{x} \frac{\partial \bar{x}_{i}}{\partial \bar{Y}_{i}} \\
& D_{i}^{T}=\overline{D_{i j}^{T}}+\frac{n^{2}}{\rho} \bar{m}_{i} \bar{m}_{j} \overline{D_{i j}^{x}} T \frac{\partial \bar{x}_{i}}{\partial T}
\end{aligned}
$$

where $\overline{D_{i j}^{x}}$ and $\overline{D_{i j}^{T}}$ are the combined diffusion coefficients due to mole fraction gradients and due to temperature gradients, respectively. It should be noted that temperature diffusion coefficient $D_{i}^{T}$ includes some of the effects of diffusion due to mole fraction gradients (the second term in equation 9) and those of diffusion due to temperature gradients $\left(\overline{D_{i j}^{T}}\right)$. Diffusion due to pressure gradients and electric fields have been reasonably neglected.

Turbulent effects in the downstream region of the discharge have been included in the flow calculations using the RNG $k-\epsilon$ model:

$$
\begin{aligned}
& \nabla \cdot(\rho k \boldsymbol{v})=\nabla \cdot\left(\alpha_{k} \mu_{e f f} \nabla k\right)+G_{k}+G_{b}-\rho \epsilon \\
& \nabla \cdot(\rho \epsilon \boldsymbol{v})=\nabla \cdot\left(\alpha_{\epsilon} \mu_{e f f} \nabla \epsilon\right)+C_{1 \epsilon} \frac{\epsilon}{k}\left(G_{k}+C_{3 \epsilon} G_{b}\right)-C_{2 \epsilon} \rho \frac{\epsilon^{2}}{k}-R_{\epsilon}
\end{aligned}
$$

where $G_{k}$ and $G_{b}$ represents the generation of turbulence kinetic energy due to the mean velocity gradients and buoyancy, respectively; the quantities $\alpha_{k}$ and $\alpha_{\epsilon}$ are the inverse effective Prandtl numbers for $k$ and $\epsilon$, respectively; $C_{1 \epsilon}, C_{2 \epsilon}$ and $C_{3 \epsilon}$ are constants with values $1.42,1.68$ and 0.09 , respectively. The turbulent viscosity, the inverse effective Prandtl numbers, the turbulent thermal conductivity, the turbulent diffusion coefficients and the source term $R_{\epsilon}$ are computed from the RNG theory as described in [33].

Turbulent wall function has been chosen according to mesh size near the chamber and torch walls: since in this region the grid is sufficiently fine (cell characteristic length less than $0.2 \mathrm{~mm}$ ), the viscosity-affected near-wall sub-layer could be fully resolved and the transition to turbulent regions could be modeled using an enhanced wall treatment, which include the traditional two-layer zonal model [33]. 
The electromagnetic field generated by the current flowing in the coil $\left(\boldsymbol{J}_{\text {coil }}\right)$ and by the induced currents in the plasma $(\boldsymbol{J})$ can be described by means of Maxwells equations written in their vector potential formulation:

$$
\nabla^{2} \boldsymbol{A}-i \omega \mu_{0} \sigma \boldsymbol{A}+\mu_{0} \boldsymbol{J}_{\text {coil }}=0
$$

where $\mu_{0}$ is the magnetic permeability of the free space $\left(4 \pi 10^{-7} \mathrm{H} / \mathrm{m}\right), \sigma$ is the plasma electrical conductivity, and $\omega=2 \pi f, f$ being the frequency of the electromagnetic field. The electric field complex phasor $\boldsymbol{E}$ and the magnetic field complex phasor $\boldsymbol{B}$ are obtained from the vector potential complex phasor $\boldsymbol{A}$ with the following expressions: $\boldsymbol{E}=-i \omega \boldsymbol{A}, \boldsymbol{B}=\nabla \times \boldsymbol{A}$. In this work, we have used the simplified Ohm's law $\boldsymbol{J}=\sigma \boldsymbol{E}$.

\subsection{Computational domain and boundary conditions}

The domain considered in the calculations includes a PL-35 torch and a nonaxysimmetric reaction chamber with two observation windows (OW1 and OW2) and a lateral gas outlet tube. A schematic of the computational domain is reported in figure 1. The origin of z-axis is located at the top of the torch.
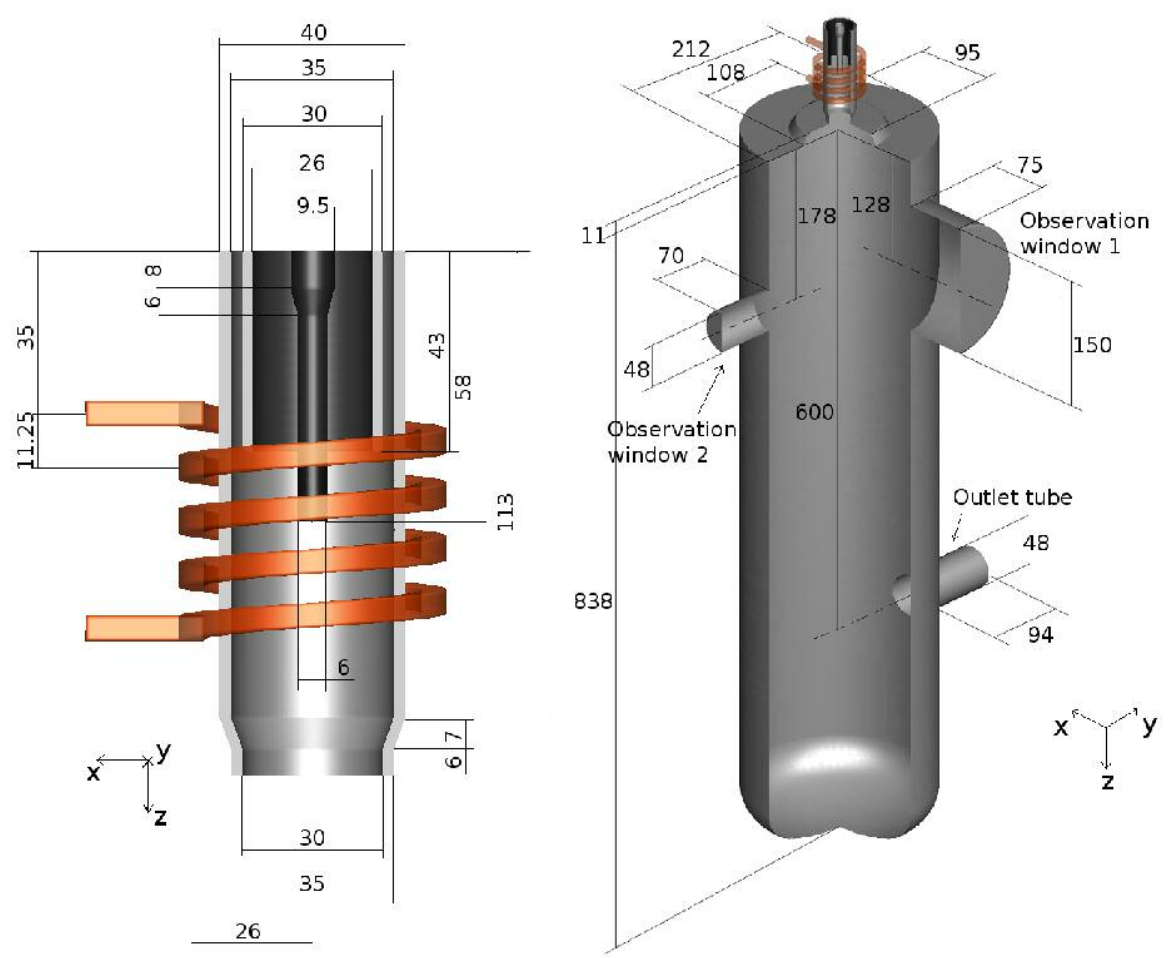

Figure 1. Detail of the PL-35 torch geometry and reaction chamber geometry (dimensions in $\mathrm{mm}$ ).

Gas is supplied to the torch through three inlets: carrier gas from the axially movable probe tip, primary gas from the inlet between the probe and the quartz tube and sheath gas from the inlet between the quartz and ceramic tubes; mass flow rates 
are $2.5 \mathrm{slpm}$ of $A r, 15 \mathrm{slpm}$ of $A r$ and $60 \mathrm{slpm}$ of $A r+4.5 \mathrm{slpm}$ of $H_{2}$ for carrier gas, central gas and sheath gas, respectively. A no-slip boundary condition is assumed on internal walls.

In order to reduce the total number of cells in the computation grid, the inlet regions of the primary and secondary gas ( 8 separate injection points for the tangential injection of the primary gas and 18 points for the axial injection of the secondary gas) have been idealized with two annular inlets with uniform gas injection, since it has been shown that results are only slightly sensible to this simplification [11].

The equation of energy has been solved including in the domain the solid regions inside the quartz and ceramic tubes, whereas the EM field has been computed using the extended field approach [34], thus solving the EM equations in a cylindrical domain around the torch (150 $\mathrm{mm}$ diameter, $113 \mathrm{~mm}$ height) with vanishing vector potential on its surface. A fixed temperature $(300 \mathrm{~K})$ has been imposed at the internal walls of the chamber and at the external walls of the torch. The torch and the reaction chamber operate at atmospheric pressure.

\subsection{Plasma properties}

Plasma thermodynamic and transport properties have been computed using 4th order Chapman-Enskog method, including $\mathrm{Ar}, \mathrm{Ar}{ }^{+}, \mathrm{H}_{2}, \mathrm{H}, \mathrm{H}^{+}$and electrons in the computation of composition [35]. Combined diffusion coefficients have been computed following Murphy [6]. In order to carry out the computation of equilibrium composition, data for partition function calculations have been obtained from JANAF tables [36] and NIST database [37]. Each iteration, plasma properties have been updated on the basis of the local temperature and local mass fraction of hydrogen in the mixture.

Radiation losses have been taken in account using data reported by Beulens et al [38] for atmospheric pressure plasmas. Radiation losses due to the presence of hydrogen have been neglected because, to the knowledge of the authors, no reliable radiation power data are available for argon-hydrogen mixtures and radiative emission due to hydrogen is substantially lower than that of argon [39]; moreover, in these simulations, hydrogen contribution to radiation can be reasonably neglected owing to small mass fraction of this gas (maximum $Y_{H}=0.0045$ ).

\section{Results and discussion}

Computations have been carried out for a plasma source operating at $3 \mathrm{MHz}$ (case $\mathrm{C} 1$ ) and for the same system with coil current frequency set to $13.56 \mathrm{MHz}$ (case C2). In both cases, the current intensity has been adjusted to make the total Joule power dissipated in the plasma discharge equal to $15 \mathrm{~kW}$ : in case $\mathrm{C} 1$ the current is $210 \mathrm{~A}$ whereas in case $\mathrm{C} 2$, as a result of the higher frequency, its value must be set at $117 \mathrm{~A}$. 


\subsection{Three-dimensional effects on temperature and velocity fields inside the torch}

In figure 2 the temperature field on two orthogonal planes passing through the axis of the torch for case $\mathrm{C} 1$ and $\mathrm{C} 2$ is reported. The maximum temperature for case $\mathrm{C} 1$ $(11713 \mathrm{~K})$ is located approximately at the same axial position of the probe tip $(\mathrm{z}=60$ $\mathrm{mm})$, whereas for case $\mathrm{C} 2$ the maximum temperature $(11606 \mathrm{~K})$ is reached at $\mathrm{z}=49$ $\mathrm{mm}$; in both cases, owing to the shielding effect of the induced currents, the maximum temperature is located at an off-axis position $(\mathrm{r}=9 \mathrm{~mm}$ and $\mathrm{r}=10 \mathrm{~mm}$ for case $\mathrm{C} 1$ and $\mathrm{C} 2$, respectively). As shown in the $\mathrm{x}-\mathrm{y}$ cross sections reported in figures 2-c and 2-f, at the torch outlet the distribution of temperature is strongly deviated in the positive y-direction for the case at $3 \mathrm{MHz}$, whereas it is almost axisymmetric for the case with 13.56 MHz. As can be seen from temperature distributions reported on the cross sections at $58 \mathrm{~mm}$ and $85 \mathrm{~mm}$, the non-axisymmentry for the case $\mathrm{C} 1$ is lower in the mid-coil region of the torch than at the outlet, whereas for case C2 it is more pronounced at $\mathrm{z}$ $=58 \mathrm{~mm}$.

Logarithmic contours of Joule dissipation and Lorentz forces for case C1 and C2 are reported in figures 3 and 4, respectively; according to previous works on simulation of ICP torches with various frequencies imposed to the coil current [15, 40, 41], the Joule dissipation inside the torch for case $\mathrm{C} 1$ is concentrated in a larger region than for case $\mathrm{C} 2$, as a result of a bigger skin depth. A similar distribution is obtained for Lorentz forces (figures 3-c, 3-d, 4-c and 4-d), because both Joule dissipation and Lorentz forces arise in the regions characterized by higher plasma conductivity.

Temperature and Joule power distributions along the $\mathrm{x}$ and $\mathrm{y}$ axis for case $\mathrm{C} 1$ and $\mathrm{C} 2$ at $\mathrm{z}=85 \mathrm{~mm}$ are reported in figure 5 . A non-axisymmetry is present for the temperature distribution along the y-axis for the case at $3 \mathrm{MHz}(\mathrm{C} 1)$, whereas for the case $\mathrm{C} 2$ the temperature profiles along $\mathrm{x}$-axis and $\mathrm{y}$-axis are similar and almost axisymmetric. For the case at $3 \mathrm{MHz}$ the Joule power has a peak at $\mathrm{r}=0.01 \mathrm{~m}$ and high values (order of magnitude $=10^{8} \mathrm{~W} / \mathrm{m}^{3}$ ) are present also inside the hot region of the discharge, whereas for the case at $13.56 \mathrm{MHz}$ the peaks are located at $\mathrm{r}=0.013 \mathrm{~m}$ but with a strong decrease of Joule power in the central portion of the torch and negligible values for $\mathrm{r}<0.005 \mathrm{~m}$. A strong non-axisymmetry in Joule power distribution is present for both cases along the $\mathrm{y}$-axis; for case $\mathrm{C} 2$ it is located at radial coordinate greater than $0.01 \mathrm{~m}$, whereas for the case at $3 \mathrm{MHz}$ the non-axisymmetry is pronounced also inside the discharge.

Since non-axisymmetries in temperature and Joule distributions are mainly located along the y-axis direction, in figure 6 a detail of the Lorentz force field along y-axis at different $\mathrm{z}$-axis position for case $\mathrm{C} 1$ and $\mathrm{C} 2$ are reported: the higher value of the skin depth in case $\mathrm{C} 1$ leads to a larger region with high values (order of magnitude $=10^{4}$ $\left.\mathrm{N} / \mathrm{m}^{3}\right)$ of Lorentz forces $(0.005<\mathrm{r}<0.015 \mathrm{~m}$ for case $\mathrm{C} 1,0.009<\mathrm{r}<0.015$ for case $\mathrm{C} 2)$.

Since Joule power distribution, Lorentz forces and temperature field are coupled by means of the electrical conductivity field, it is difficult to state whether the non- 
axisymmetric distribution of the temperature field is the effect or the cause for other non-axisymmetries. However, the only source of non-axisymmetry in the torch is the helicoidal shape of the induction coil; a previous work by some of the authors [7] has shown that non-axisymmetric temperature distribution inside the inductively coupled plasma torch results a consequence of the unbalanced Lorentz forces due to the first and the last coil turns, which pull the discharge in opposite y-directions leading to a 'torque' on the discharge. In this work, lower maximum absolute values of Lorentz forces have been obtained for the case with higher coil current frequency. As a consequence, it can be argued that a lower torque is applied to the discharge and that fluid-dynamic inertia prevails over Lorentz forces resulting in an almost axisymmetric discharge.

In figure 7 a detailed view of velocity magnitude field inside the torch is reported for both case $\mathrm{C} 1$ and $\mathrm{C} 2$. The velocity magnitude field for case C1 is strongly deviated towards the positive y-direction as a result of the non-axisymmetric viscosity and density fields, which in turn depend on mass fraction and temperature fields. On the contrary, the velocity magnitude field is almost axisymmetric for the case $\mathrm{C} 2$. In figure 8 different components of the plasma velocity inside the torch are shown: in case C1 the nonaxisymmetric Joule power dissipation, Lorentz forces and temperature fields induce an increase in the y-component of the plasma velocity below the probe tip, whereas the $\mathrm{y}$-component of the velocity for case $\mathrm{C} 2$ and the $\mathrm{x}$-component for both cases are almost axisymmetric.

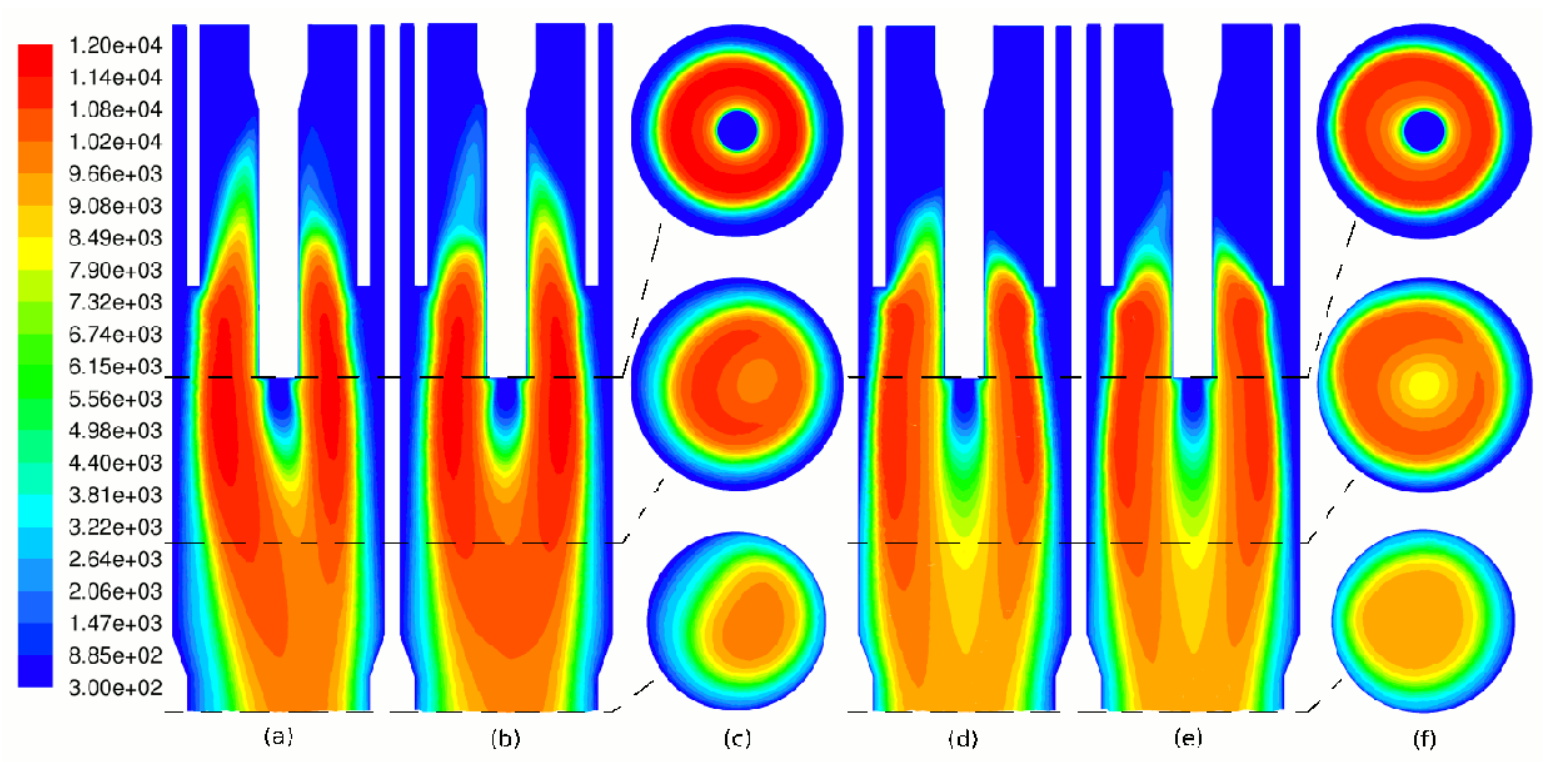

Figure 2. Detail of the temperature field $(K)$ inside the torch: case $C 1$ - plane $y-z$ (a), plane $\mathrm{x}-\mathrm{z}(\mathrm{b})$ and $\mathrm{x}-\mathrm{y}$ sections with positive $\mathrm{x}$-axis oriented to the top at $\mathrm{z}=58$ $\mathrm{mm}, \mathrm{z}=85 \mathrm{~mm}$ and $\mathrm{z}=112 \mathrm{~mm}(\mathrm{c})$; case $\mathrm{C} 2$ - plane $\mathrm{y}-\mathrm{z}(\mathrm{d})$, plane $\mathrm{x}-\mathrm{z}(\mathrm{e})$ and $\mathrm{x}-\mathrm{y}$ sections with positive $\mathrm{x}$-axis oriented to the top at $\mathrm{z}=58 \mathrm{~mm}, \mathrm{z}=85 \mathrm{~mm}$ and $\mathrm{z}=$ $112 \mathrm{~mm}(\mathrm{f})$. 


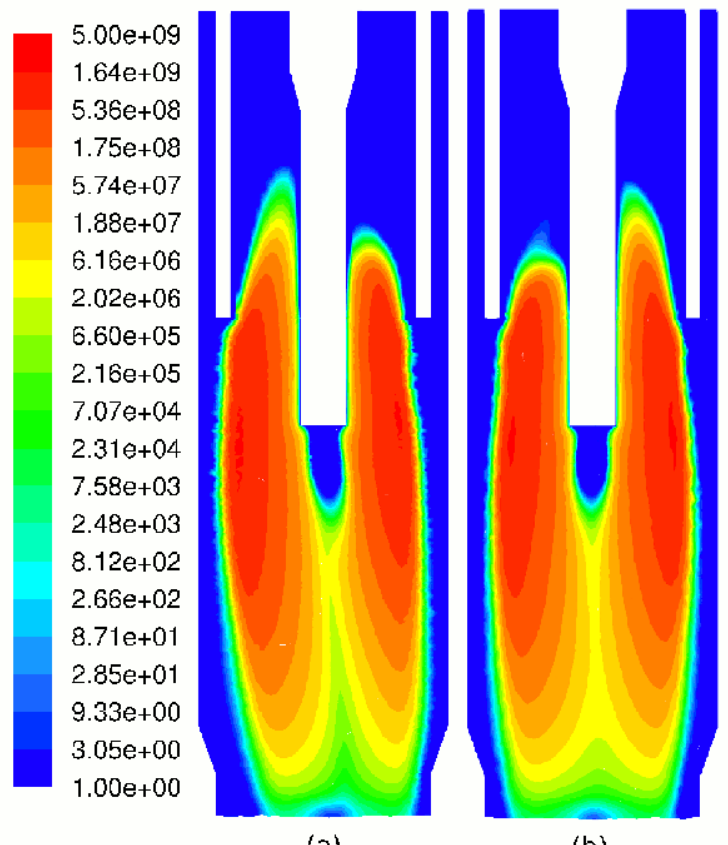

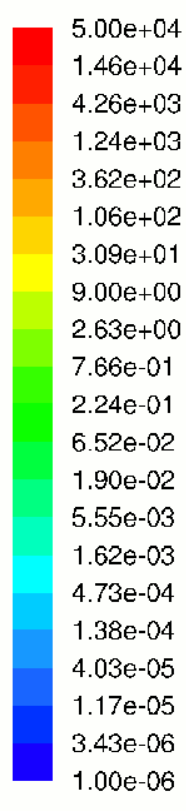

(b)

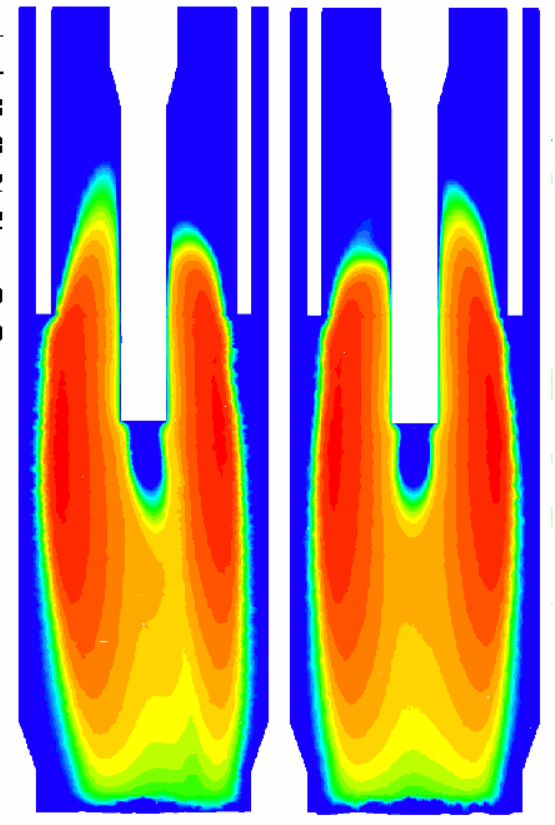

(c)

(d)

Figure 3. Case $\mathrm{C} 1$ - Detail of the Joule power $\left(W / m^{3}\right)$ inside the torch: plane $\mathrm{y}-\mathrm{z}$ (a) and plane $\mathrm{x}-\mathrm{z}$ (b); detail of the Lorentz force magnitude $\left(\mathrm{N} / \mathrm{m}^{3}\right)$ inside the torch: plane $\mathrm{y}-\mathrm{z}(\mathrm{c})$ and plane $\mathrm{x}-\mathrm{z}(\mathrm{d})$.

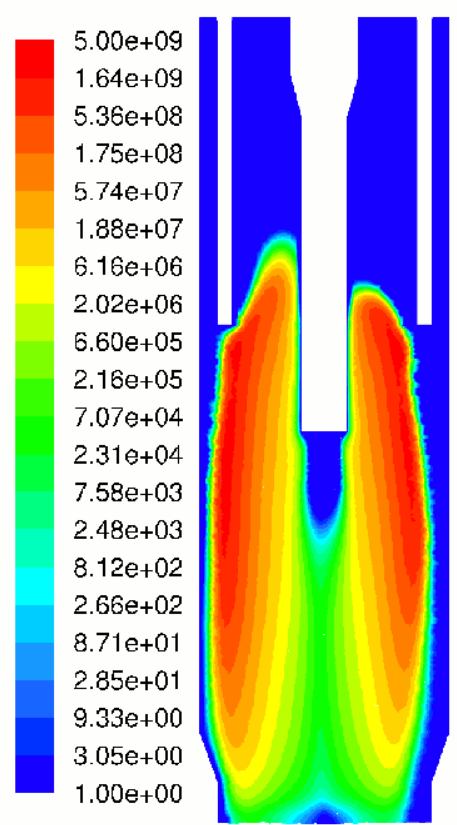

(a)

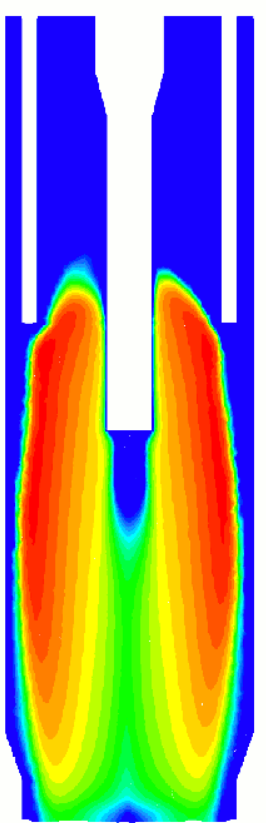

(b)

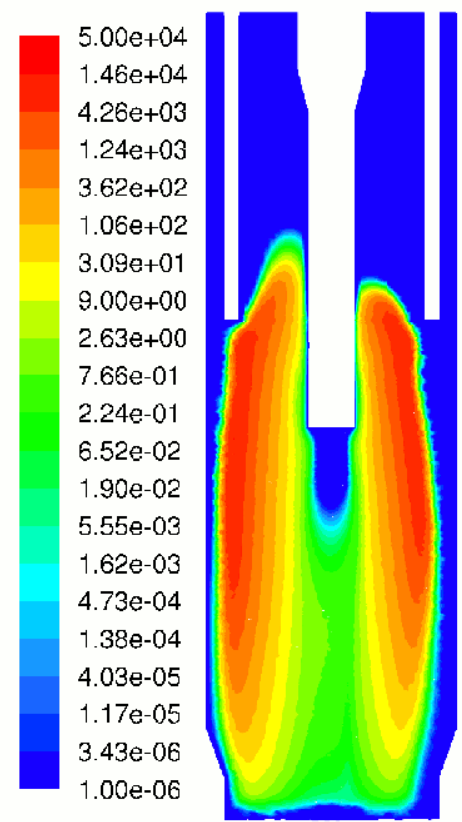

(c)

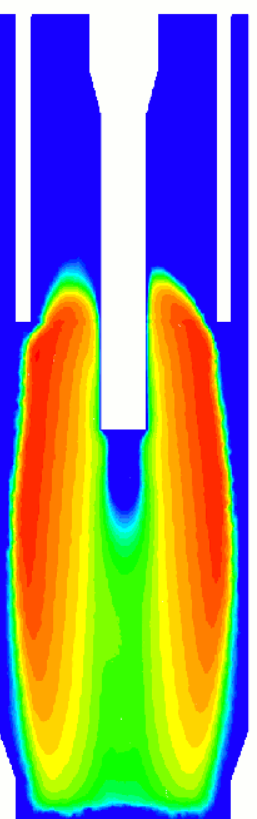

(d)

Figure 4. Case $\mathrm{C} 2$ - Detail of the Joule power $\left(\mathrm{W} / \mathrm{m}^{3}\right)$ inside the torch: plane $\mathrm{y}-\mathrm{z}$ (a) and plane $\mathrm{x}-\mathrm{z}(\mathrm{b})$; detail of the Lorentz force magnitude $\left(N / \mathrm{m}^{3}\right)$ inside the torch: plane $\mathrm{y}-\mathrm{z}(\mathrm{c})$ and plane $\mathrm{x}-\mathrm{z}(\mathrm{d})$. 

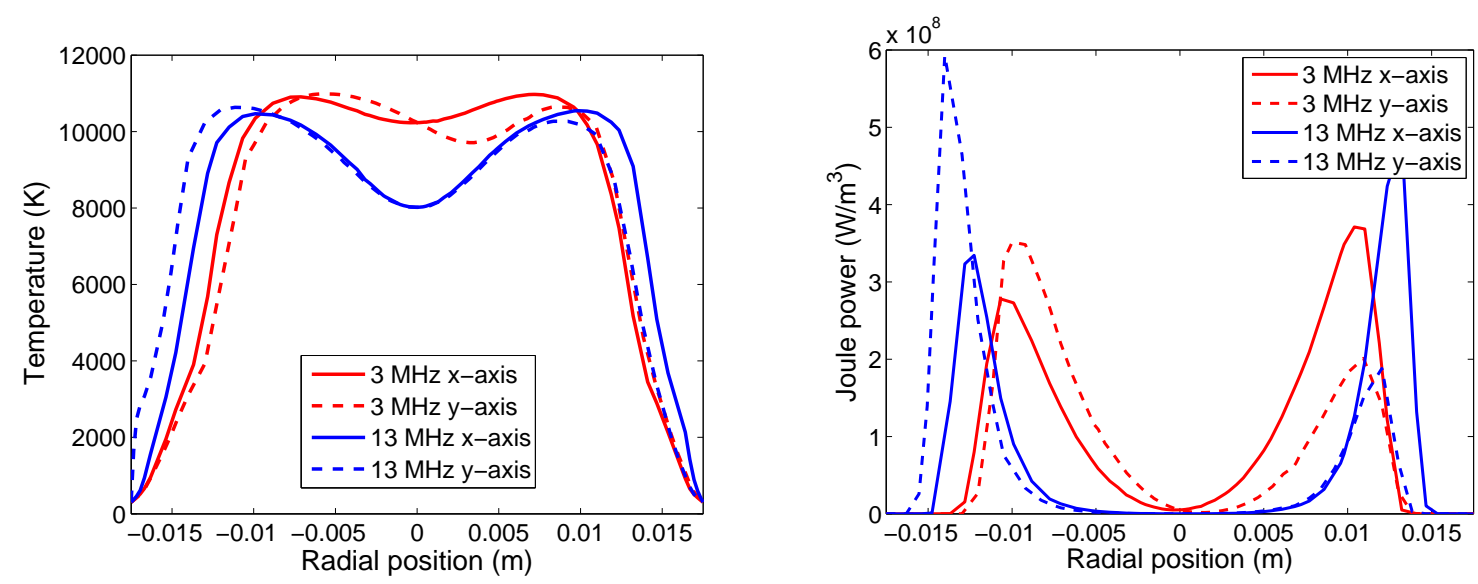

Figure 5. Temperature (left) and Joule power (right) for cases C1 and C2 along the $\mathrm{x}$-axis and the $\mathrm{y}$-axis at $\mathrm{z}=85 \mathrm{~mm}$.
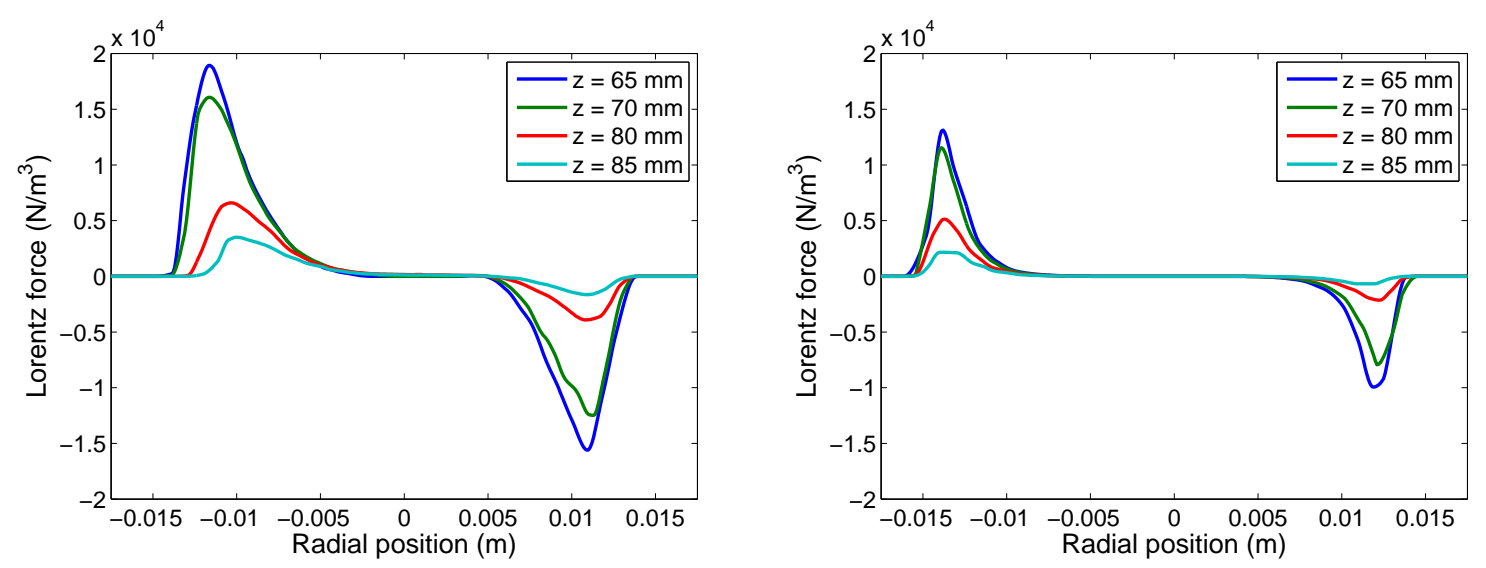

Figure 6. Lorentz forces for case $\mathrm{C} 1$ (left) and case C2 (right) along the y-axis at different z-positions.

\subsection{Temperature and velocity fields in the reaction chamber}

Figure 9 reports the temperature fields in the reaction chamber on two orthogonal planes passing through the axis of the torch, for case $\mathrm{C} 1$ and $\mathrm{C} 2$. Temperature in the downstream region of the torch for case $\mathrm{C} 1$ is generally lower than for case $\mathrm{C} 2$; in fact, the iso-surfaces at $2640 \mathrm{~K}$ extend up to $110 \mathrm{~mm}$ and $188 \mathrm{~mm}$ below the torch exit for the first and second case, respectively. This can be attributed to the lower power dissipated through radiation inside the torch: the larger region at high temperature in case $\mathrm{C} 1$ leads to a higher radiative dissipation $(7.2 \mathrm{~kW})$ with respect to case $\mathrm{C} 2(5.4 \mathrm{~kW})$ and to a lower enthalpy flux entering the reaction chamber $(6.9 \mathrm{~kW}$ for case $\mathrm{C} 1$ and $8.2 \mathrm{~kW}$ for case $\mathrm{C} 2$ ).

In the region below the torch outlet, for both case $\mathrm{C} 1$ and $\mathrm{C} 2$, the temperature field is markedly non-axisymmetric. Since in the chamber there is no heating power, a non-axisymmetric temperature distribution can be determined by advection and 


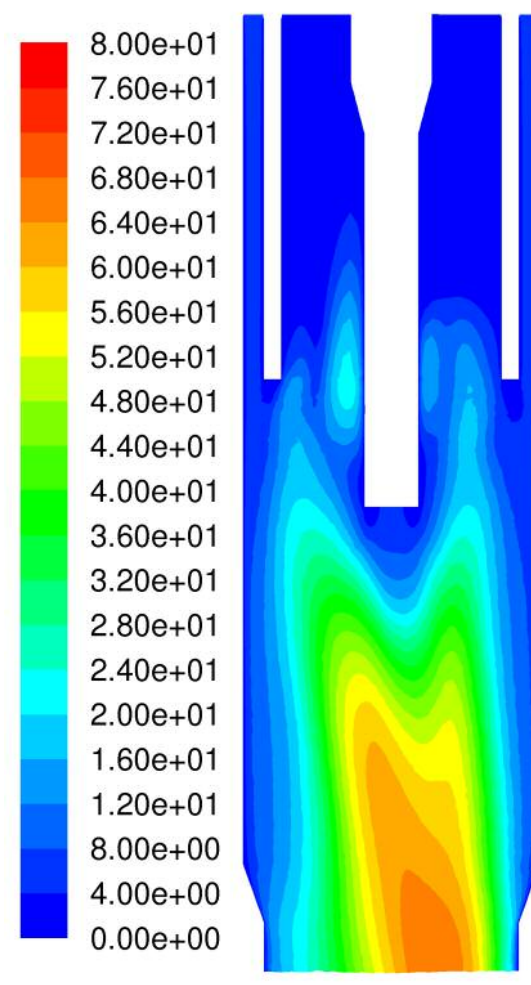

(a)

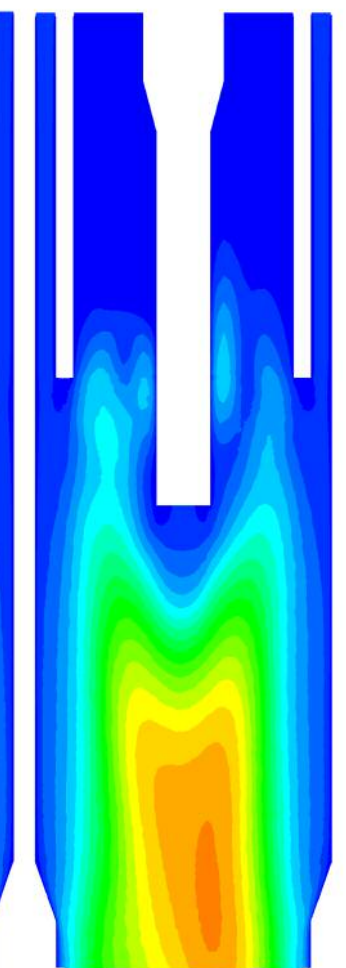

(b)

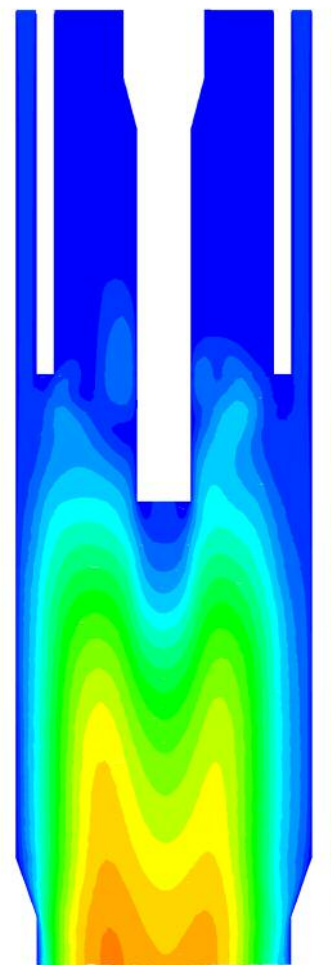

(c)

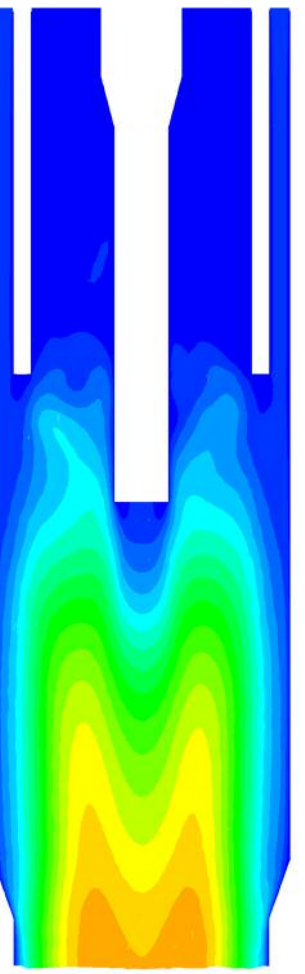

(d)

Figure 7. Detail of the field of the magnitude of the velocity $(\mathrm{m} / \mathrm{s})$ inside the torch: case C1 - plane $\mathrm{y}-\mathrm{z}(\mathrm{a})$ and plane $\mathrm{x}-\mathrm{z}(\mathrm{b})$; case $\mathrm{C} 2$ - plane $\mathrm{y}-\mathrm{z}(\mathrm{c})$ and plane $\mathrm{x}-\mathrm{z}(\mathrm{d})$.

conduction only: as far as in both cases conduction losses are determined by the same chamber geometry, different directions of the plasma tail temperature distribution can be attributed mainly to different recirculation flow patterns in the chamber.

In figure 10 different flow patterns in the reaction chamber are reported for $\mathrm{C} 1$ and $\mathrm{C} 2$. In case $\mathrm{C} 1$ the flow exiting the torch is deviated towards both the observation window OW1 and the outlet tube of the chamber, as can be seen from the pathlines released from the plasma gas inlet shown in figures 10-a and 10-b; the temperature isosurfaces in the reaction chamber for case C1 (figure 9-a and 9-b) are similarly deviated. In case $\mathrm{C} 2$ both the flow pattern and the temperature iso-surfaces are deviated in the direction of observation windows OW1 and OW2 (figures 9-c, 9-d, 10-a and 10-b).

In the reaction chamber the energy transport by conduction is enhanced by turbulent diffusion. A direct correlation exist between turbulent thermal conductivity and turbulent viscosity. In figure 11 the turbulent viscosity ratio fields in the reaction chamber for case $\mathrm{C} 1$ and $\mathrm{C} 2$ are reported. This parameter is defined as the ratio between turbulent and molecular viscosities and can be considered as an index of turbulence intensity. Below the torch outlet the turbulent viscosity ratio reaches high values (greater than 50) as a consequence of recirculation flows, for both case $\mathrm{C} 1$ and $\mathrm{C} 2$. 


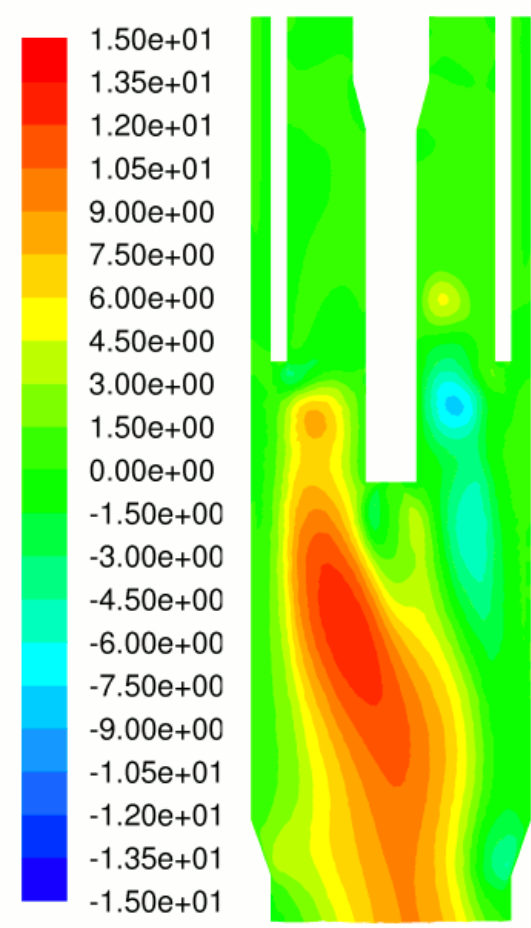

(a)

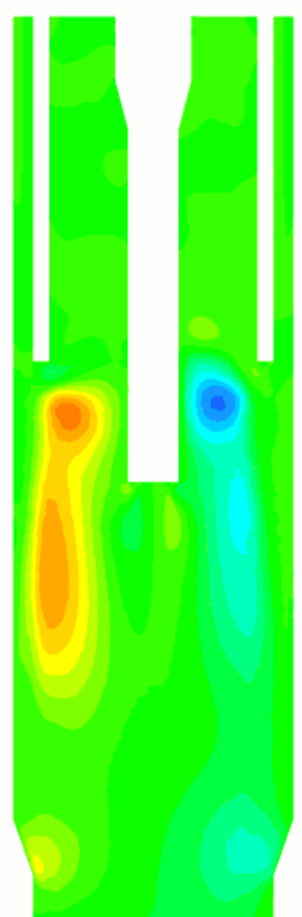

(b)

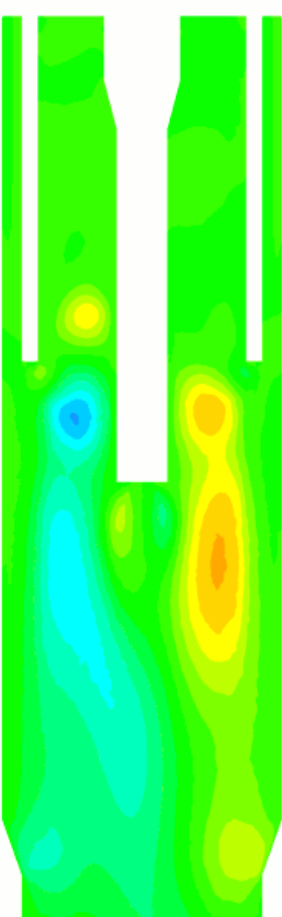

(c)

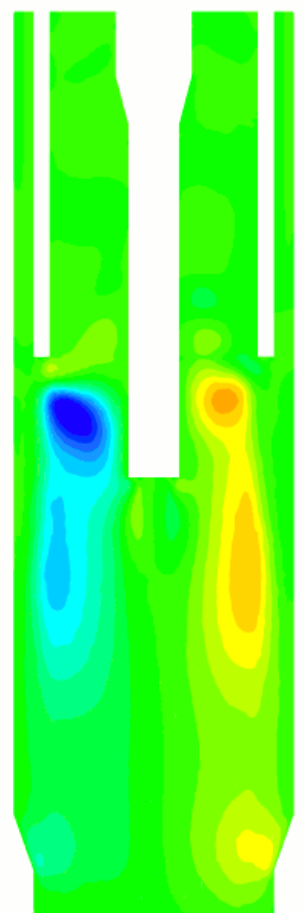

(d)

Figure 8. Velocity field components $(\mathrm{m} / \mathrm{s})$ : y-component on the y-z plane for cases C1 (a) and C2 (b); x-component on the x-z plane for cases C1 (c) and C2 (d).

\subsection{Mass fraction fields and demixing effects}

Three-dimensional effects in the temperature field lead to non-axisymmetric mass fraction fields as shown in figure 12 and 13 for case $\mathrm{C} 1$ and $\mathrm{C} 2$, respectively. Hydrogen mass fraction profile along $\mathrm{y}$-axis at $\mathrm{z}=95 \mathrm{~mm}$ is reported in figure 14 .

As can be seen from these pictures, for both case $\mathrm{C} 1$ and $\mathrm{C} 2$ a strong accumulation of hydrogen can be evidenced near the torch wall (figure 12-e); however, for case C1 the region with higher mass fraction of hydrogen $\left(Y_{H}>0.003\right)$ is larger for negative yaxis positions than for positive ones (figures 12-c and 14); in case $\mathrm{C} 2$ the accumulation is even stronger than in case C1 (see figure 14) but the region with higher values of mass fraction is more axisymmetric (figure 13-e); on the contrary, in case C2 a nonaxysimmetric distribution has been obtained for the region with lower values of the hydrogen mass fraction $\left(Y_{H}<0.003\right)$, as can be seen in figures 13-c, 13-e and 14. In the reaction chamber three-dimensional composition fields arise near the top wall and in the observation window OW2 (figures 12-a, 12-b, 13-a and 13-b).

Hydrogen injected from the secondary gas inlet moves towards the central region of the torch according to three mechanisms: diffusion due to mass fraction gradients, turbulent diffusion and thermal diffusion. The latter, as shown in figure 15, generally entails the diffusion of argon towards lower temperature regions; however, on the 


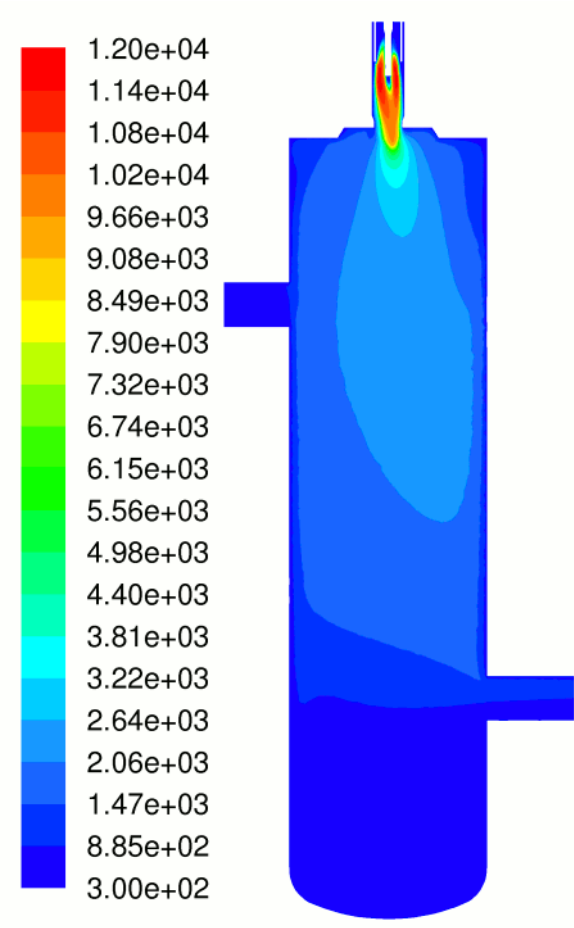

(a)

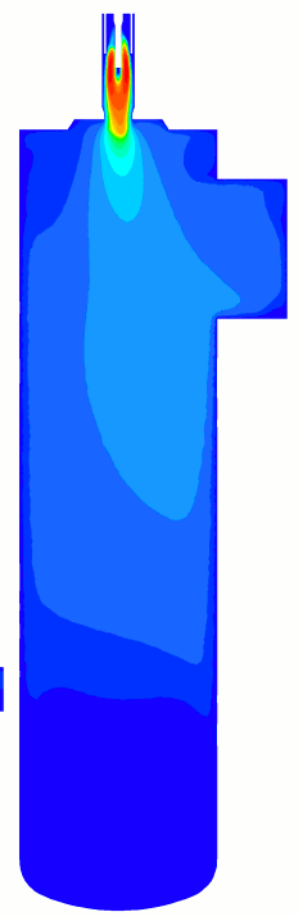

(b)

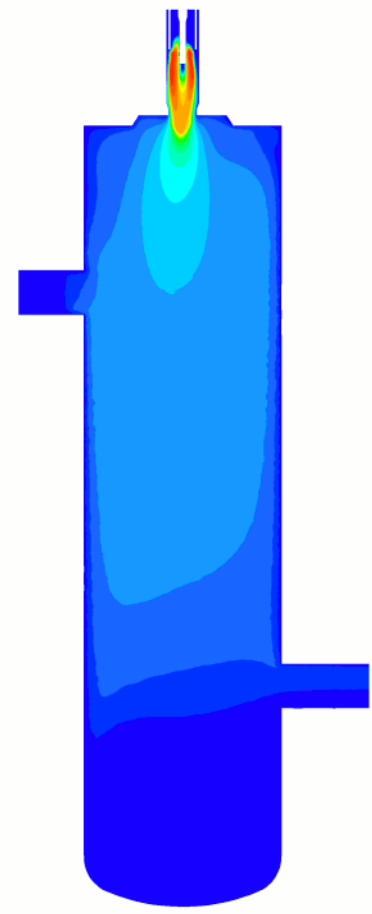

(c)

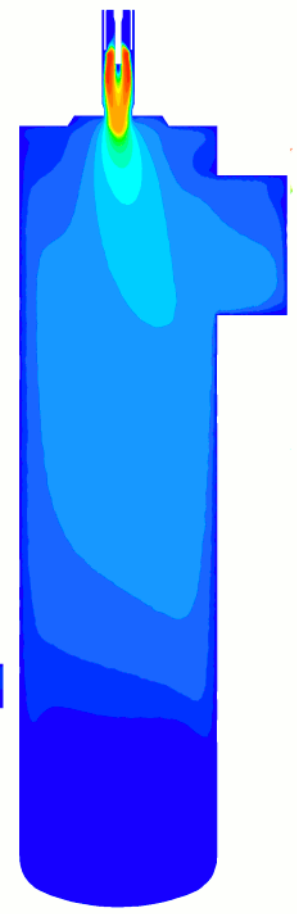

(d)

Figure 9. Temperature field $(K)$ in the reaction chamber: case $\mathrm{C} 1$ - plane $\mathrm{y}-\mathrm{z}$ (a) and plane $\mathrm{x}-\mathrm{z}(\mathrm{b})$; case $\mathrm{C} 2$ - plane $\mathrm{y}-\mathrm{z}(\mathrm{c})$, plane $\mathrm{x}-\mathrm{z}(\mathrm{d})$.

contrary, for a temperature range between $2000 \mathrm{~K}$ and $5000 \mathrm{~K}$, the temperature diffusion coefficient for argon $D_{i}^{T}$ is negative, as a result of hydrogen dissociation, and the argon is pushed towards higher temperature regions. In this range of temperature, it is known that negative values of the temperature derivative of the argon mole fraction exist for argon-hydrogen mixtures [42], leading to negative values of the temperature diffusion coefficient for argon (see equation 9). In figure 16 different contribution to temperature diffusion coefficient have been reported for the temperature range $300 \mathrm{~K}-12000 \mathrm{~K}$ : thermal diffusion contribution due to temperature gradients $\left(\overline{D_{i j}^{T}}\right)$ is always positive whereas the one due to mole fraction gradients (the second term in equation 9) is generally null with exception of dissociation and ionization temperature ranges where it assumes negative and positive values, respectively. Temperature diffusion coefficient is responsible for the effect of demixing.

As can be seen in figures 12-a, 12-b, 13-a and 12-b, at the outlet of the quartz tube, hydrogen diffuses towards the central region of the plasma discharge mainly as a result of mass fraction and temperature gradients, since turbulence in this region is negligible (see figure 11); since there are strong temperature gradients near the internal wall of the torch, thermal diffusion acts mainly as an obstacle to the diffusion of hydrogen towards the central region.

Negative values of argon temperature diffusion coefficient around $3300 \mathrm{~K}$ and 


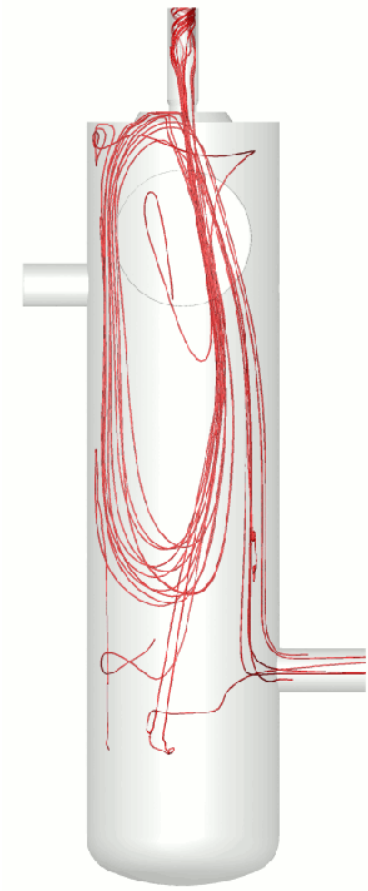

(a)

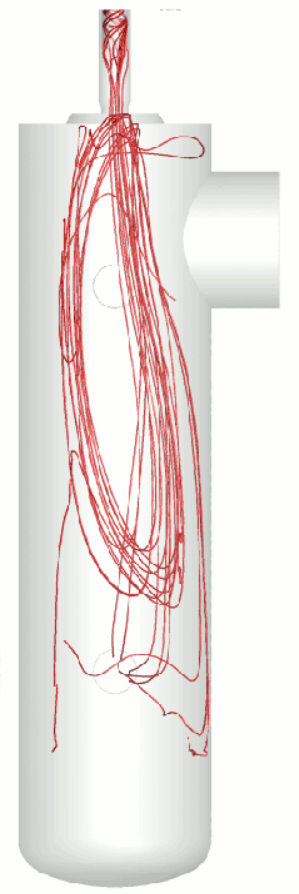

(b)

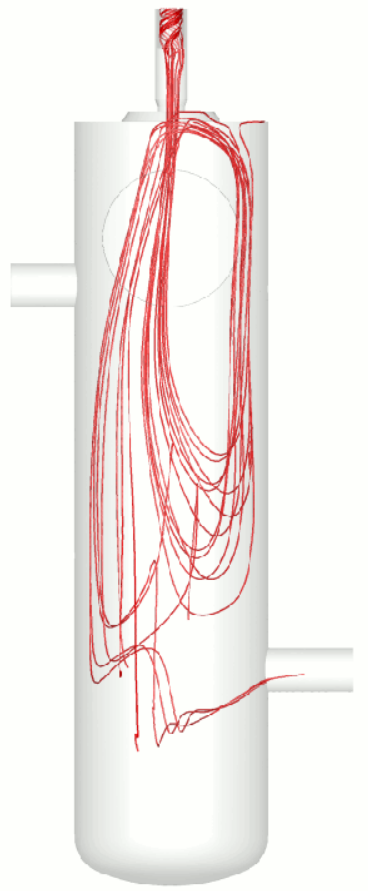

(c)

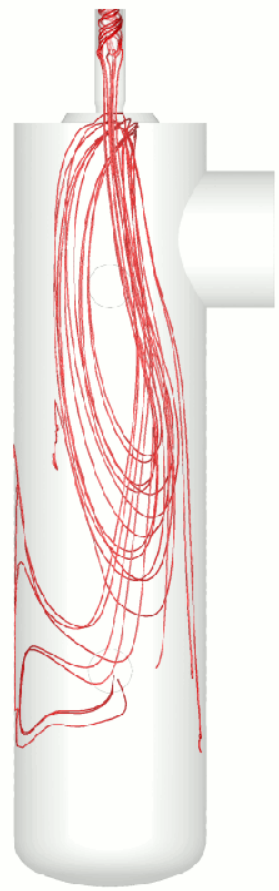

(d)

Figure 10. Pathlines released from plasma gas inlet: case $C 1-y-z$ view (a), $x-z$ view (b); case C2 - y-z view (c), x-z view (d).

positive values for lower temperature result in an accumulation of hydrogen in the temperature region where the coefficient is null $(\mathrm{T}=2000 \mathrm{~K})$. In fact, hydrogen mass fraction has its maximum value $\left(Y_{H}=0.0045\right)$ in the fringes of the discharge and this is greater than the mass fraction of hydrogen in the inlet sheath gas $\left(Y_{H}\right.$ at inlet $\left.=0.00374\right)$. In figure 14 hydrogen mass fraction and argon temperature diffusion coefficient along the $\mathrm{y}$-axis at $\mathrm{z}=85 \mathrm{~mm}$ have been reported: peaks in hydrogen mass fraction are strongly correlated with negative peaks in argon temperature diffusion coefficients and they are located where temperature is about $2000 \mathrm{~K}$, i.e. the just below the dissociation temperature range.

As can be seen in figure 15, for temperature higher than $4500 \mathrm{~K}$ the argon temperature diffusion coefficient is positive. The point of transition between negative and positive values is a dispersion point for hydrogen: in presence of a temperature gradient, hydrogen at temperature lower than the transition temperature is pushed towards lower temperature zones whereas hydrogen at temperature higher than the transition temperature is pushed towards higher temperature ones; this results in a hydrogen dispersion towards lower or higher temperatures. This is clear from figure 14 where mass fraction of hydrogen has been plotted: for case $\mathrm{C} 1$ a local minima which correspond to dispersion points are found at $\mathrm{y}=-0.011 \mathrm{~m}$ and $\mathrm{y}=0.013 \mathrm{~m}$ whereas for case C2 they are located at $\mathrm{y}=-0.015 \mathrm{~m}$ and $\mathrm{y}=0.012 \mathrm{~m}$.

Similar results have been obtained also by Chen for a different ICP torch 


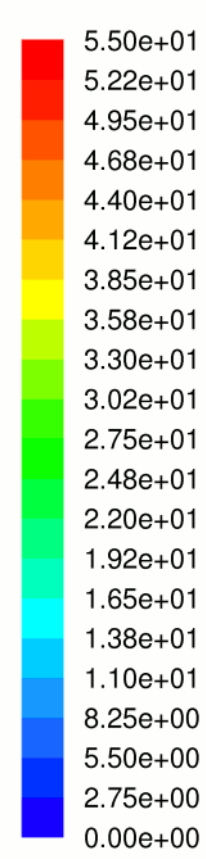

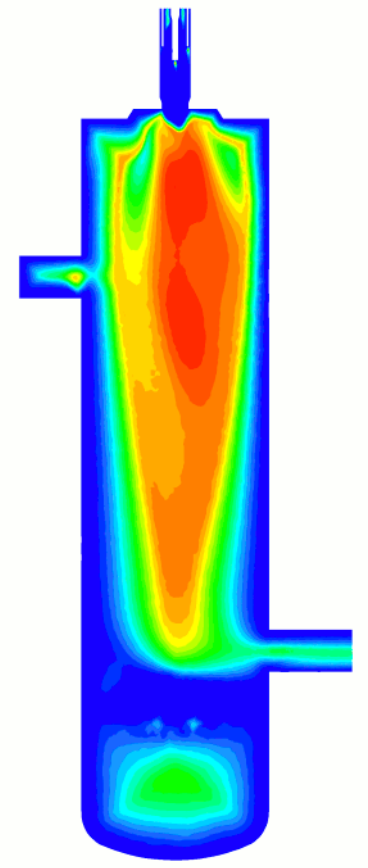

(a)

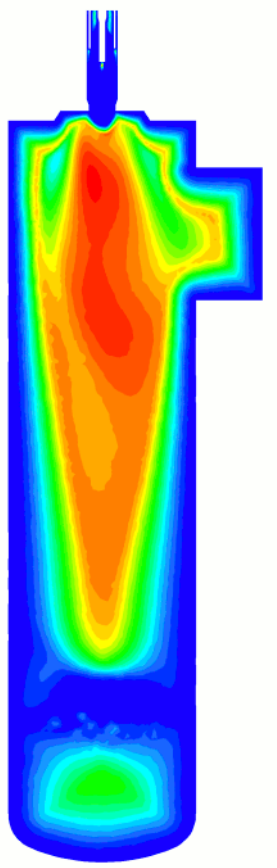

(b)

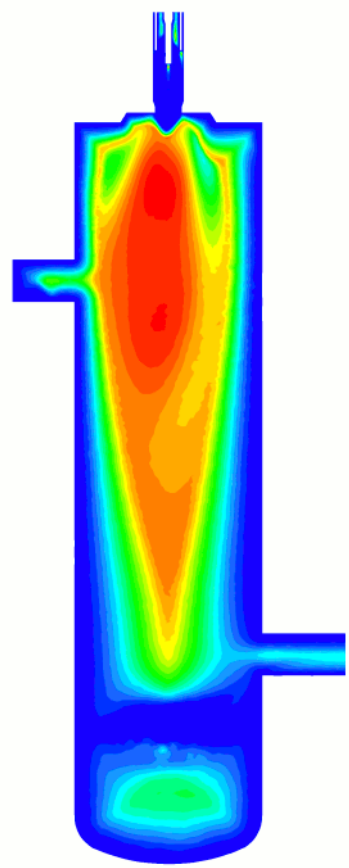

(c)

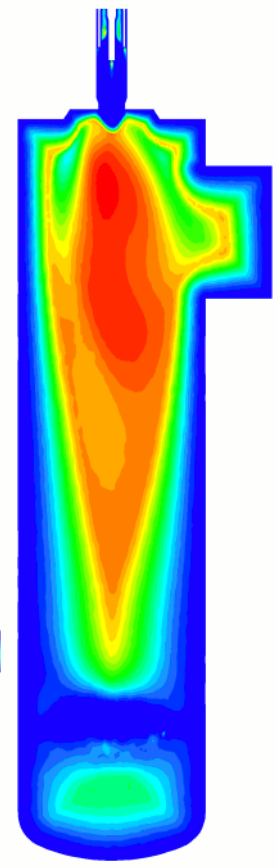

(d)

Figure 11. Turbulent viscosity ratio: case $\mathrm{C} 1$ - plane $\mathrm{y}-\mathrm{z}(\mathrm{a})$ and plane $\mathrm{x}-\mathrm{z}(\mathrm{b})$; case C2 - plane $\mathrm{y}-\mathrm{z}(\mathrm{c})$ and plane $\mathrm{x}-\mathrm{z}(\mathrm{d})$.

configuration [28] and the accumulation of hydrogen in the cold boundary layer of a thermal spray torch was simulated by Ghorui et al [43] using a two-temperature combined diffusion approach. These results are in agreement also with previous investigations by Murphy [42] in which a peak of hydrogen mass fraction has been predicted in the low-temperature fringes of a free burning arc.

In the reaction chamber, hydrogen diffusion is dominated by turbulence: the viscosity ratio reaches values of the order of 50 where the gas expands in the reaction chamber, as shown in figure 11, and the hydrogen is almost completely mixed (figures 12-a, 12-b, 13-a and 13-b). In the fringes of the plasma plume in the reaction chamber, where temperature is below the dissociation range, thermal diffusion pushes hydrogen (almost completely in its molecular form) towards higher temperature regions.

In figure 17 the mass fraction of hydrogen is reported for a fictitious case where thermal diffusion due to temperature gradients has been neglected. The temperature coefficient used has been plotted in figure 16 for $Y_{H}=0.002$. For both cases $\mathrm{C} 1$ and $\mathrm{C} 2$, the mass fraction in the chamber is almost constant, as a result of null temperature diffusion coefficient below the dissociation temperature range. In the torch, the accumulation of hydrogen in the fringes of the discharge is enhanced, since the positive contribution to the temperature coefficient due to temperature gradients has been neglected. Thus, according to previous investigations by Murphy on free-burning arcs [42], the accumulation of hydrogen in the fringes of the discharge can be attributed 
mainly to diffusion due to mole fraction gradients.

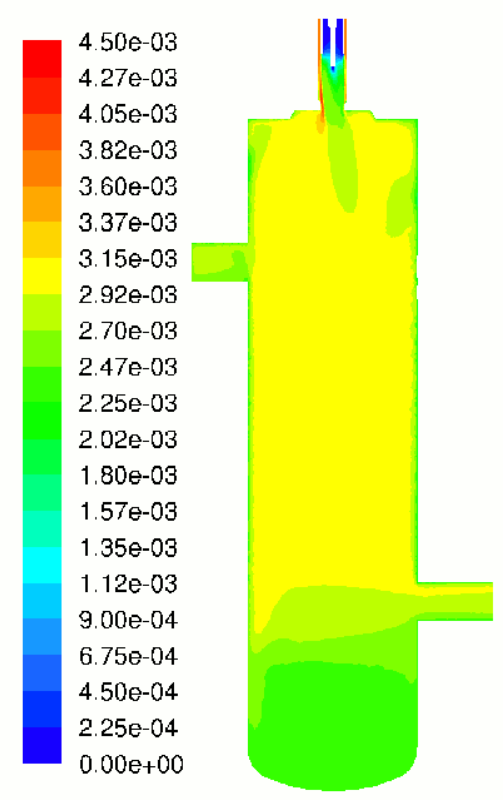

(a)

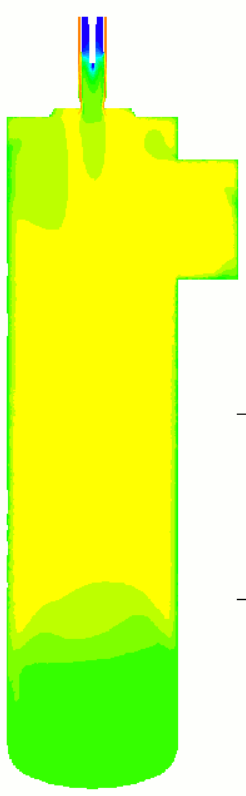

(b)

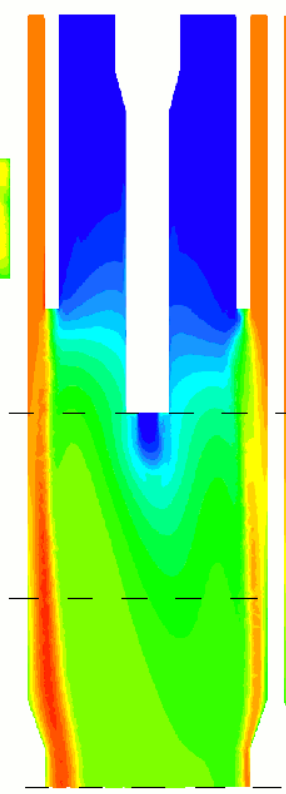

(c)

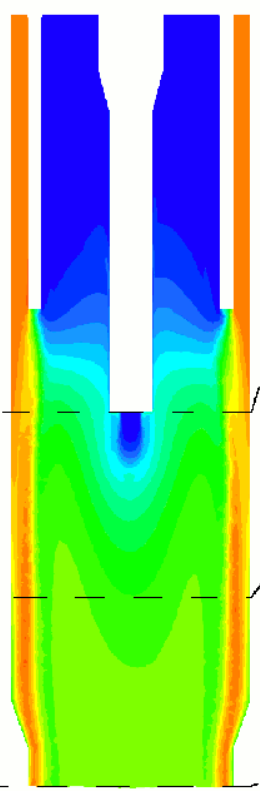

(d)

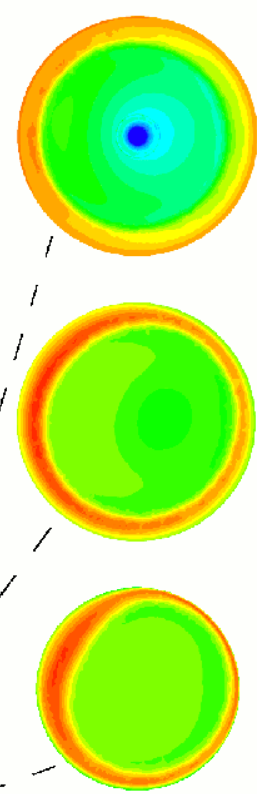

(e)

Figure 12. Case C1 - Mass fraction of hydrogen: plane $y-z$ (a) and plane $x-z(b)$; detail of the mass fraction of hydrogen inside the torch: plane $y-z(c)$, plane $x-z$ (d) and $\mathrm{x}-\mathrm{y}$ sections with positive $\mathrm{x}$-axis oriented to the top at $\mathrm{z}=58 \mathrm{~mm}, \mathrm{z}=85 \mathrm{~mm}$ and $\mathrm{z}=112 \mathrm{~mm}(\mathrm{e})$.

\section{Conclusions}

A fully three-dimensional model of a commercial ICP torch with laboratory scale reaction chamber has been developed using a commercial CFD software (FLUENT ${ }^{\circledR}$ ). Numerical results, which completely characterize the electromagnetic and thermo-fluiddynamic behavior of the system, are presented for an atmospheric pressure argonhydrogen mixture using the RNG $\mathrm{k}-\epsilon$ turbulence model and the combined diffusion approach of Murphy. Two different cases have been considered with different coil current frequency ( $3 \mathrm{MHz}$ and $13.56 \mathrm{MHz}$ ), the other operating conditions being fixed (mass ow rates, total Joule power dissipated, inlet gas composition).

This approach has allowed a deeper insight in the three-dimensional effects of the coil current frequency: non-axisimmetrical velocity, temperature, Joule dissipation and Lorentz force fields have been found for current frequency equal to $3 \mathrm{MHz}$, whereas for the case at higher frequency the discharge in the torch is almost axisymmetric. At higher frequency, the lower absolute value of Lorentz forces and the smaller volume of the discharge where they are applied, induces a lower unbalance between the force exerted on the discharge by the first and the last coil turn; thus, it is argued that fluiddynamic inertia prevails over the torque applied to the discharge by the coil and the 


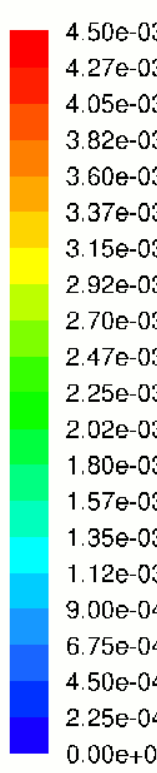

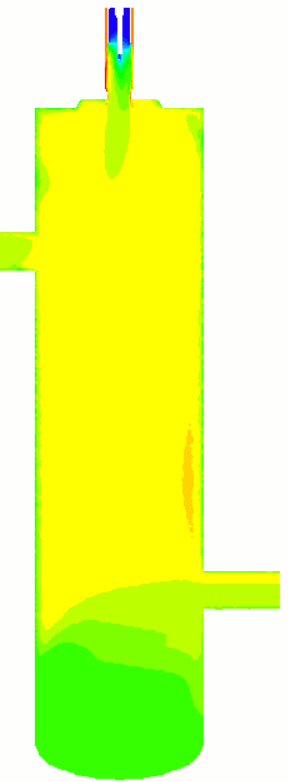

(a)

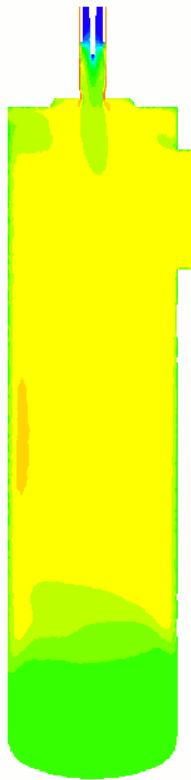

(b)

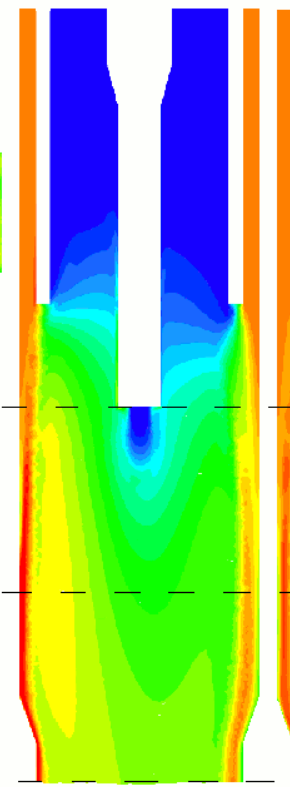

(c)

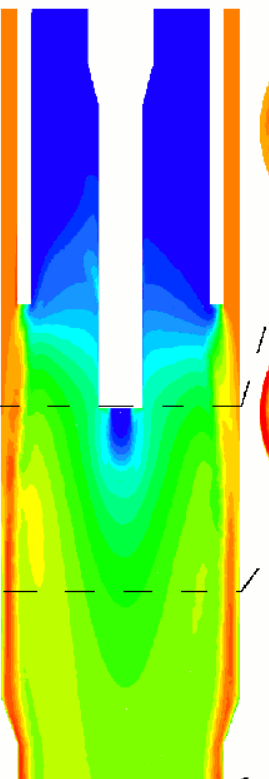

(d)

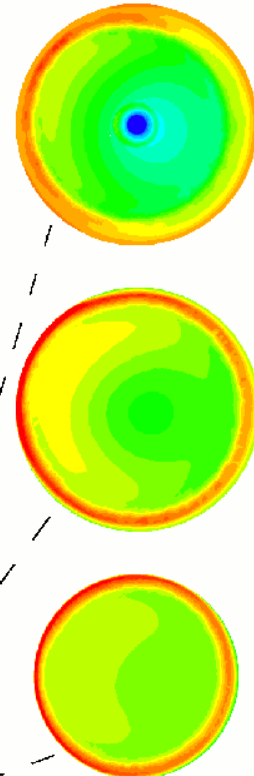

(e)

Figure 13. Case C2 - Mass fraction of hydrogen: plane $y-z$ (a) and plane $x-z(b)$; detail of the mass fraction of hydrogen inside the torch: plane $y-z(c)$, plane $x-z(d)$ and $\mathrm{x}-\mathrm{y}$ sections with positive $\mathrm{x}$-axis oriented to the top at $\mathrm{z}=58 \mathrm{~mm}, \mathrm{z}=85 \mathrm{~mm}$ and $\mathrm{z}=112 \mathrm{~mm}(\mathrm{e})$.

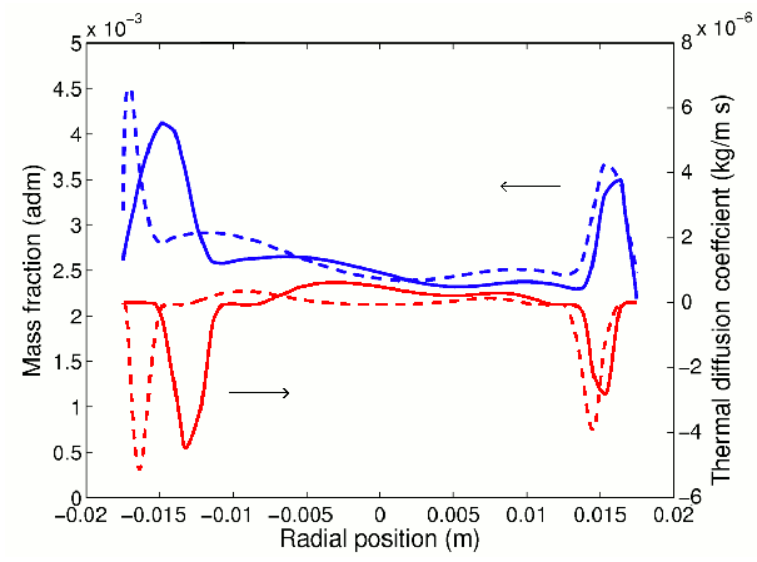

Figure 14. Hydrogen mass fraction and argon temperature diffusion coefficient along $\mathrm{y}$-axis at $\mathrm{z}=95 \mathrm{~mm}$ : case $\mathrm{C} 1 \longrightarrow$, case $\mathrm{C} 2-\cdots$.

resulting temperature field is more axisymmetric.

Moreover, the distribution of hydrogen mass fraction inside the torch and inside the reaction chamber has been accurately predicted, in agreement with previous works which accounted for demixing effects in thermal plasmas. Different diffusion mechanisms have been investigated, considering the effects on mass fraction field of thermal diffusion due to mole fraction gradients and temperature gradients. 


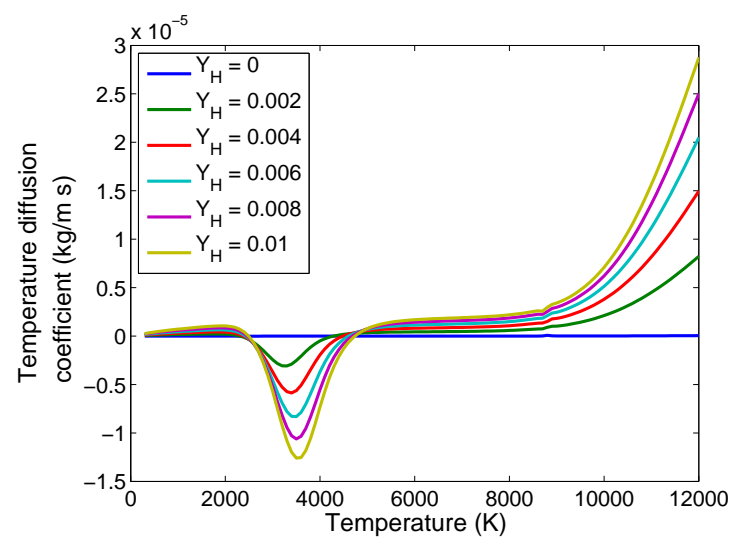

Figure 15. Argon temperature diffusion coefficients $\left(D_{A r}^{T}\right)$ as a function of temperature for argon-hydrogen mixtures, for constant mass fractions of hydrogen.

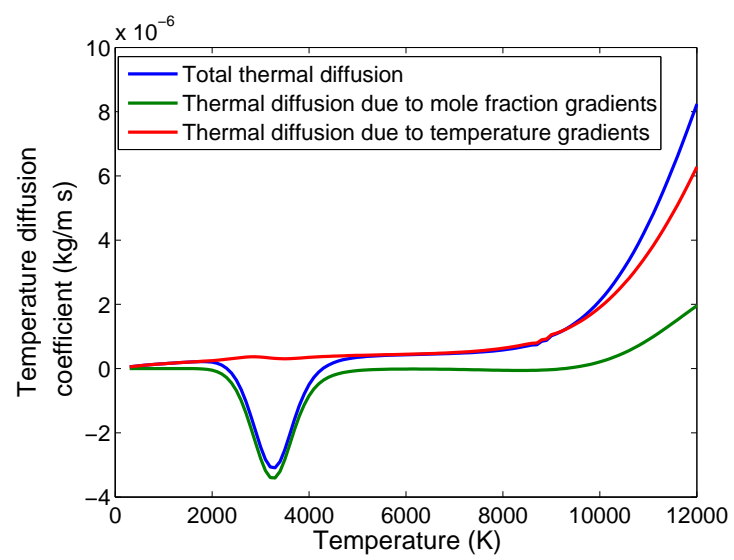

Figure 16. Different contributions to argon temperature diffusion coefficient $\left(D_{A r}^{T}\right)$ as a function of temperature for argon-hydrogen mixtures, for constant mass fraction of hydrogen $\left(Y_{H}=0.002\right)$.

Finally, the temperature field in the reaction chamber has been simulated: its threedimensional shape has been correlated to different types of recirculation flow arising when a non-axisymmetric reaction chamber, which include a lateral outlet tube, is used.

Accurate modeling of devices characterized by inherently non-axisymmetric geometries such as inductively coupled plasma torches, requires the implementation of three-dimensional codes to analyze the magnitude of non-axisymmetric effects on plasma properties arising under different operating conditions. This is true in particular for the modeling of powder treatment processes such as powder spheroidization and nano-particles production, since the behavior of injected raw materials and of nucleated aerosols in the reaction chamber depends strongly on temperature and velocity fields. 


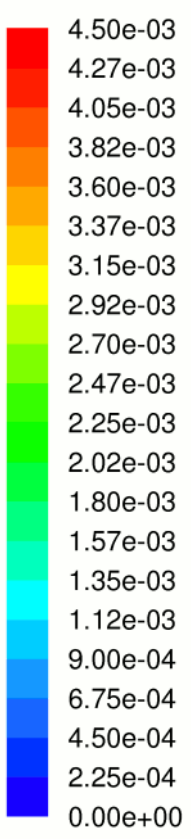

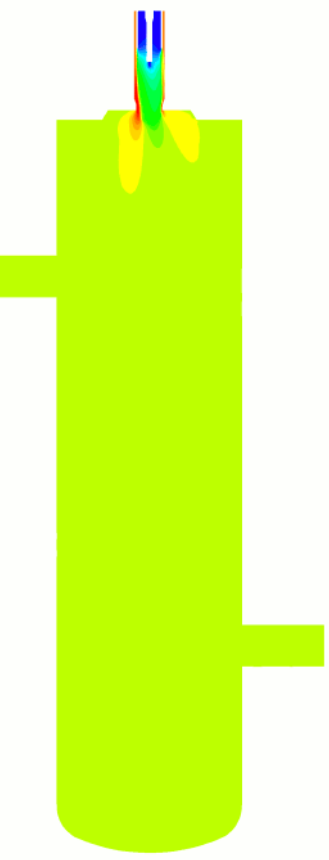

(a)

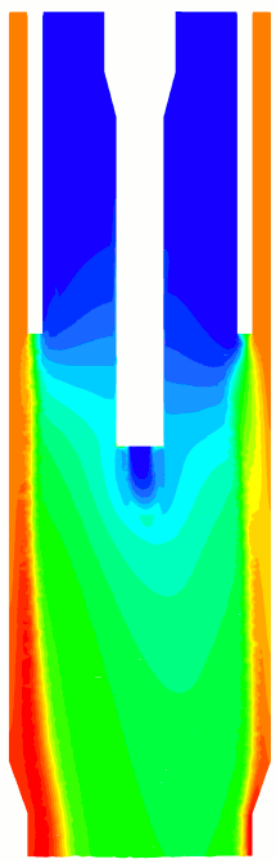

(b)

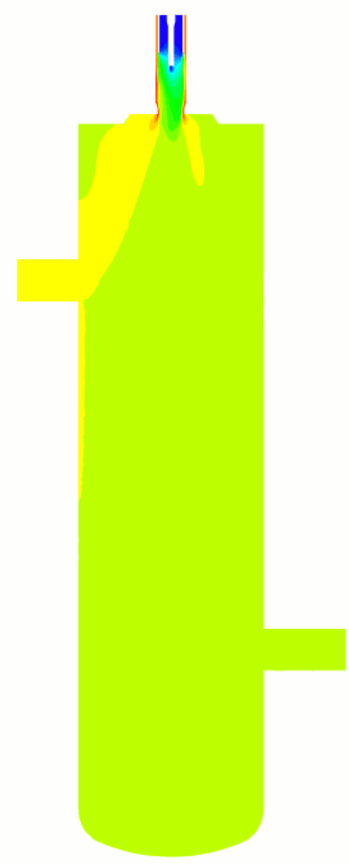

(c)

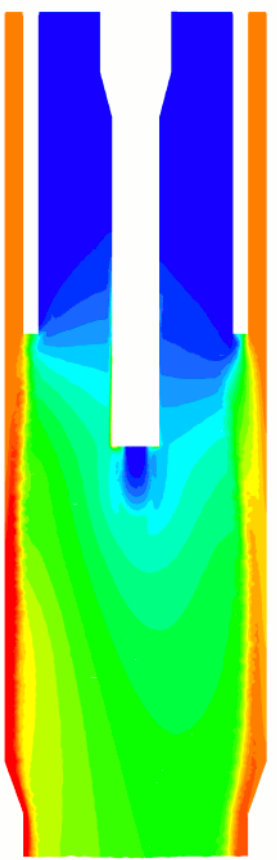

(d)

Figure 17. Mass fraction of hydrogen on plane $y-z$ neglecting thermal diffusion due to temperature gradients: case C1 - chamber view (a) and torch view (b); case C2 chamber view (c) and torch view (d).

\section{References}

[1] Boulos M I 1997 High Temp. Mater. Process. 1 17-39

[2] Murphy A B, Boulos M I, Colombo V, Fauchais P, Ghedini E, Gleizes A, Mostaghimi J, Proulx P and Schram D C 2008 High Temperature Material Processes 12 255-336

[3] Colombo V, Ghedini E and Mostaghimi J 2008 IEEE Trans. Plasma Sci. 36 1040-1

[4] Ye R, Ishigaki T, Taguchi H, Ito S, Murphy A B and Lange H 2006 J. Appl. Phys. 100103303

[5] Murphy A B 1993 Phys. Rev. E 483594

[6] Murphy A B 2001 J. Phys. D: Appl. Phys. 34 R151

[7] Bernardi D, Colombo V, Ghedini E and Mentrelli A 2003 Eur. J. Phys. D 22 119-25

[8] Bernardi D, Colombo V, Ghedini E and Mentrelli A 2003 Eur. J. Phys. D 25 279-85

[9] Bernardi D, Colombo V, Ghedini E, Mentrelli A and Trombetti T 2004 Eur. J. Phys. D 28 423-33

[10] Bernardi D, Colombo V, Ghedini E, Mentrelli A and Trombetti T 2005 IEEE Trans. Plasma Sci. 33 424-5

[11] Colombo V and Ghedini E 2007 High Temperature Material Processes 11 283-96

[12] Njah Z, Mostaghimi J and Boulos M I 1993 Int. J. Heat Mass Transfer 36 3909-19

[13] Njah Z, Mostaghimi J, Faghri M and Boulos M I 1993 Int. J. Heat Mass Transfer 36 3897-907

[14] Siegmann St, Leparoux M, Schreuders C, Shin J W and Rohr L 2005 Proceedings of 17th International Symposium on Plasma Chemistry (ISPC 17) Toronto, Ontario, Canada

[15] Bernardi D, Colombo V, Ghedini E and Mentrelli A 2003 Eur. J. Phys. D 25 271-7

[16] Bernardi D, Colombo V, Ghedini E and Mentrelli A 2005 Pure Appl. Chem. 77 359-72

[17] Karoly Z and Szepvolgyi J 2003 Powder Technology 132 211-15

[18] Shin J W, Miyazoe H, Leparoux M, Siegmann St, Dorier J L and Hollenstein Ch 2006 Plasma Sources Sci. Technol. 15 441-9 
[19] Fan X, Gitzhofer E and Boulos M I 1998 J. Therm. Spray Technol. 7 247-53

[20] Ye R, Ishigaki T, Jurewicz J, Proulx P and Boulos M I 2004 Plasma Chem. Plasma Process. 24 $555-71$

[21] Ramshaw J D and Chang C H 1996 Phys. Rev E 53 6382-8

[22] Tanaka Y 2002 J. Phys. D: Appl. Phys. 35 468-76

[23] Tanaka Y 2004 J. Phys. D: Appl. Phys. 37 1190-205

[24] Watanabe T and Sugimoto N 2004 Thin Solid Films 457 201-8

[25] Atsuchi N, Shigeta M and Watanabe T 2006 Int. J. Heat Mass Transfer 49 1073-82

[26] Watanabe T, Shigeta M and Atsuchi N 2006 Int. J. Heat Mass Transfer 49 4867-76

[27] Xue S, Proulx P, Murphy A B and Boulos M I 2005 Proc. 17th International Symposium on Plasma Chemistry, Toronto, Canada

[28] Chen X, Sugasawa M and Kikukawa N 1998 J. Phys. D: Appl. Phys. 31 1187-96

[29] Siegmann S, Girshick S L, Szepvolgyi J, Leparoux M, Shin J W, Schreuders C, Rohr L, Ishigaki T, Jurewicz J W, Habib M, Baroud G, Gitzhofer F, Kambara M, Diaz J M A, Yoshida T 2008 High Temperature Material Processes 12 205-54

[30] Xue S, Proulx P and Boulos M I 2003 Proc. 16th International Symposium on Plasma Chemistry, Taormina, Italy

[31] Ye R, Murphy A B and Ishigaki T 2007 Plasma Chem. Plasma Process. 27 189-204

[32] Rini P, Vanden Abeele D and Degrez G 2006, J. Thermophys. Heat Trans. 20 31-40

[33] FLUENT 6.3 User's Guide 2006, Fluent Inc. Centerra Resource Park 10 Cavendish Court, Lebanon, NH 03766

[34] Bernardi D, Colombo V, Ghedini E and Mentrelli A 2003 Eur. J. Phys. D 27 55-72

[35] Colombo V, Ghedini E and Sanibondi P 2009 J. Phys. D: Appl. Phys. 42055213 (12pp)

[36] Chase M W, Davies C A, Downey J R, Frurip D J, McDonald R A and Syverud A N 1985 JANAF Thermochemical Tables 3rd ed. J. Phys. Chem. Ref. Data 14

[37] Ralchenko Y, Kramida A E, Reader J and NIST ASD Team 2008 NIST Atomic Spectra Database (version 3.1.5), [Online]. Available: http://physics.nist.gov/PhysRefData/ASD/index.html. National Institute of Standards and Technology, Gaithersburg, MD.

[38] Beulens J J, Milojevic D, Schram D C and Vallinga P M 1991 Phys. Fluids B 3254857

[39] Essoltani A, Proulx P, Boulos M I and Gleizes A 1995 Plasma Chem. Plasma Process. 14 301-15

[40] Shigeta M, Sato T and Nishiyama H 2004 Int. J. Heat Mass Transfer 4770716

[41] Bolot R, Coddet C, Schreuders C, Leparoux M and Siegmann S 2007 Journal of Thermal Spray Technology 16 690-7

[42] Murphy A B 1997 Phys. Rev. E 55 7473-94

[43] Ghorui S, Vysohlid M, Heberlein J V R and Pfender E 2007 Phys. Rev. E 76016404 